\title{
Mindfulness and Connection Training During Preservice Teacher Education Reduces Early Career Teacher Attrition Three Years Later
}

Matthew J. Hirshberg ${ }^{1,2}$, Lisa Flook ${ }^{1}$, Reka Sundaram-Stukel ${ }^{3}$, Richard J. Davidson ${ }^{1}$

1. Center for Healthy Minds, University of Wisconsin-Madison

2. Department of Educational Psychology, University of Wisconsin-Madison

3. Department of Economics, University of Wisconsin-Madison

\begin{abstract}
Author Note
Matthew J. Hirshberg (D) https://orcid.org/0000-0001-9070-1270

Lisa Flook (iD https://orcid.org/0000-0001-7832-090X

Reka Sundaram-Stukel ihttps://orcid.org/0000-0002-9006-8548

Richard J. Davidson (Dhttps://orcid.org/0000-0002-8506-4964

Richard J. Davidson is the founder, president, and serves on the board of directors for the non-profit organization, Healthy Minds Innovations, Inc. This study was supported by the Mind \& Life Institute (2014-Varela-Hirshberg), The Trust for the Meditation Process (15-08), and a National Academy of Education / Spencer Foundation Postdoctoral Research Fellowship to the first author, and by generous individual donations to the Center for Healthy Minds. We thank Lori Gustafson, Devon Hase, Lisa Thomas-Prince, M. Elizabeth Graue, Jane Sachs, Heather Williams, Sophia Diamantis, and our undergraduate research assistants. No donors, either anonymous or identified, have participated in the design, conduct, or reporting of research results
\end{abstract} in this manuscript.

Correspondence concerning this article should be addressed to: 
Matthew J. Hirshberg, Center for Healthy Minds, University of Wisconsin-Madison, 625 W.

Washington Avenue, Madison, WI, 53705, Email: hirshberg@wisc.edu; Phone: (608)-262-0035.

Preprint version 01.19.2023. This manuscript is currently in review. Please do not copy or cite without author permission. 


\begin{abstract}
Early career teacher attrition disrupts school continuity, precludes many of those who leave from achieving expertise, and drains economic resources from school systems. In a cluster randomized controlled trial $(k=8, n=98)$, we examined the impact of a nine-week meditation-based intervention on undergraduate preservice teachers' persistence as professional teachers fouryears later. Regardless of modeling strategy, the odds of intervention participants teaching threeyears into their careers were around six times greater than control participants (Odds ratios $=4.44$ to $7.78, p=.006-p=.013)$. In benefit-cost analyses, we estimate that for every $\$ 1$ spent on the intervention, hiring districts saved $\$ 3.43$ in replacement teacher costs. Implications for teacher education educational systems are discussed.
\end{abstract}

Keywords: Mindfulness, Teacher education; Teacher attrition; Teacher retention; benefit-cost analysis 


\section{Mindfulness and Connection Training During Preservice Teacher Education Reduces Early Career Teacher Attrition Three Years Later}

Approximately 3.7 million public school teachers educate over 56 million children in American schools (US Department of Education, 2021). Teachers explain more variance in student outcomes than any other school-based factor (Rockoff, 2004), placing teachers at the center of many policies to improve student outcomes. Although improving teacher quality and longevity, especially through the first few years on the job, have been focal policy concerns, teacher attrition rates have not declined over the last 20 years (Ingersoll et al., 2018). With predictions of substantial retirements amongst the aging teacher corps (García \& Weiss, 2020) and a majority of all teachers now contemplating leaving teaching earlier than expected (Walker, 2022), the importance of keeping teachers in the profession is amplified by growing concerns about shortages of qualified teachers (Dee \& Goldhaber, 2017). If provisions within undergraduate teacher education could help reduce attrition rates, many of the challenges schools face related to teacher turnover and attrition could be preemptively mitigated.

Improving teacher quality and longevity are interrelated concerns. Most teacher improvements occur during the first few years on the job (Papay \& Kraft, 2015). Estimates suggest that around $44 \%$ of teachers leave the profession within their first five years or approximately 8\% per year, on average (Ingersoll et al., 2018). At any given time, a considerable proportion of America's teaching corps is comprised of new, inexperienced teachers learning on the job who are likely to leave and be replaced by new, inexperienced teachers (Henry et al., 2011). In theory early career attrition could act as a beneficial natural sorting mechanism (Adnot et al., 2017), but research suggests that high levels of staff attrition have pervasive detrimental effects, affecting the achievement of all students, not only students placed with a new or 
inexperienced teacher (Ronfeldt et al., 2013; Sorensen \& Ladd, 2020).

Early career teacher attrition also contributes to systematic educational inequities. Attrition rates are substantially higher in schools serving high proportions of economically disadvantaged students (Ingersoll et al., 2018; Sorensen \& Ladd, 2020). Accordingly, students from lower income backgrounds may be more likely to experience less effective teachers (Goldhaber et al., 2015). These same students are more likely to attend schools with fewer resources. As a consequence, already under-resourced schools are forced to allocate a greater share of limited resources to teacher recruitment and training, magnifying the consequences of teacher attrition.

Replacing teachers is also expensive. In inflation adjusted 2022 dollars, per teacher replacement costs range from $\$ 6,838.79$ in low-cost St. Lucie County School District, Florida (Shockley et al., 2006) to \$22,631.06 in urban Milwaukee, Wisconsin (Barnes et al., 2007). These estimates likely underestimate the real costs however, because they do not account for lost human capital or the likelihood that a leaving, more experienced teacher will be replaced by a new, less experienced and ineffective one (Simon \& Johnson, 2015). In this study, we observed that assigning undergraduate preservice teachers (PSTs) to a secular meditation-based intervention (MBI) partially integrated into their teacher education program significantly reduced attrition during the critical first three-years of professional teaching, producing substantial economic benefits to the employing school districts.

\section{Individual and Structural Predictors of Career Attrition and Persistence}

The causes of early career teacher attrition are complex. Individual characteristics of the teacher as well as structural characteristics of teacher education programs and later the schools in which teachers work have each been associated with career outcomes. At the individual teacher 
level, teachers whose teaching quality was rated more highly upon career entry (Vagi et al., 2019), who believed that they were well prepared by their teacher education program (DeAngelis et al., 2013) and who reported higher levels of conscientiousness (Kim et al., 2019) are more likely to persist. Similarly, individual characteristics such as personality facets, self-efficacy, and grit explain small but meaningful amounts of variance in teacher effects on student achievement (Duckworth et al., 2009; Kim et al., 2019).

Compared to individual-level predictors, research on structural predictors of attrition and persistence is more mature. Out of this body of research a number of structural predictors of teacher career outcomes have been identified. For example, research has established that work conditions are associated with teacher longevity, both in terms of career attrition and school turnover (i.e., moving from one school or district to another while continuing as a teacher (Johnson, 2012; Simon \& Johnson, 2015). More specifically, school resources (e.g., the quality of facilities, materials) and well-organized, collegial and supportive schools are associated with both teacher longevity and performance (Borman \& Dowling, 2008; Johnson et al., 2012; Simon \& Johnson, 2015). Research has also documented associations between perceived administrative support and teacher longevity (Boyd et al., 2011; Wynn et al., 2007). Principal turnover is itself associated with spikes in teacher turnover (DeMatthews et al., 2022). Hiring, and onboarding practices are another source of variance in teacher outcomes; schools that tend to hire teachers later (i.e., closer to the beginning of or during a school year) tend to have higher levels of attrition (Borman \& Dowling, 2008; Kraft et al., 2016).

Many structural factors covary (Boyd et al., 2011). For instance, low-resource schools also tend to hire teachers later, and as noted earlier, frequently need to hire more teachers overall, leading to systemic instability in staffing. School climate, the overall sense of the working (and 
for students, learning environment) is an additional predictor of teacher turnover and attrition (Wynn et al., 2007). High levels of staff churn are in turn associated with lower overall school climate (Guin, 2004).

Paralleling the research on individual and structural predictors of attrition, attempts to promote teacher persistence have focused on structural reforms. Recent examples of structural reforms attempting to improve teacher persistence include early career induction programs, merit pay systems, and reforming hiring practices (Nguyen et al., 2020). Some of these reforms have shown promise. For instance, in a meta-analysis, merit pay programs reduced attrition by 1.6 percentage points (Nguyen et al., 2020; 15\% in hard to staff schools). Another recent example is to ensure cooperating teachers during PST education are high quality teachers (indicated by observation and/or value-added scores). Assigning PSTs to high quality cooperating teachers leads to PSTs feeling better prepared to teach and may improve their early career effectiveness (Ronfeldt, 2021; Ronfeldt et al., 2020), but returns to career persistence have not yet been studied.

There are many good reasons to pursue structural reforms. It is nevertheless curious that comparatively little attention has been placed on promoting teacher characteristics that are associated with persistence. Concerns about putting the onus on teachers to thrive in suboptimal contexts are well placed, but such concerns do not obviate the potential role that such an approach might have. If teachers arrive in schools better resourced to handle the challenges of the profession, teacher outcomes, students, and many of the structural characteristics that lead teachers to leave (e.g., staff instability, school climate) may benefit. Moreover, addressing the complex causes of teacher attrition can probably only be accomplished through complementary individual and structural-level reforms. Whereas addressing many of the structural causes of 
teacher attrition require state or federal legislation such as changes to school funding allocation processes, making intervention difficult and slow, approaches like the one studied can be more easily implemented within existing teacher education or professional development.

Although intervening within teacher education may be more feasible than addressing structural factors associated with persistence, it is not necessarily easy. Perhaps most saliently, teacher education programs have limited time to fulfill the educational and clinical requirements needed for preservice candidates to earn licensure. Undergraduate programs are typically fulltime endeavors with rigorous schedules. This study approached this challenge by designing a meditation-based intervention (MBI) for pre-service teachers that was synergistic with and could be integrated into extant teacher education.

\section{Teacher Stress}

Teaching is widely characterized as a complex, interactive, and emotional practice that requires knowledge and skills (Baumert \& Kunter, 2013). As a consequence, teaching can be stressful and many teachers report high levels of stress, anxiety, and depressive symptoms (Kush et a., 2022; Masked, 2023). New teachers in particular report that learning to manage a classroom is stressful and overwhelming (Greenberg, Putnam, \& Walsh, 2014). In turn, elevated symptoms of distress are associated with the intention to leave teaching as well as actual career attrition (Ingersoll et al., 2018; Ryan et al., 2017; Masked, 2023). Reducing teacher stress may be a lever to enhancing career longevity. In preservice teachers, strengthening dispositions that allow adaptation to professional teaching while managing the stressors of the profession may prevent individual-level causes of early career attrition.

Folkman and Lazarus' transactional model of stress and coping (Folkman \& Lazarus, 1988; Lazarus \& Folkman, 1984) describes the processes by which individuals perceive (i.e., 
appraise) and respond (i.e., cope) to environmental stressors. According to this model, individual's first appraise the salience of a situation to their stress and well-being. When a situation is appraised as potentially stressful, second-order appraisals consist of potential responses to the perceived threat (coping strategies). Rates of teacher stress suggest that teachers appraise many situations as stressful. We hope that a teacher, when faced with a stressful classroom experience, will respond (i.e., enact a behavior) that is responsive to the needs of the student and the classroom while maintaining focus on learning goals. In other words, we hope that they will enact an effective instructional practice.

The ability of a teacher to respond effectively depends on a number of factors. The teacher must have knowledge of effective classroom management and instructional strategies (e.g., pedagogical and content knowledge). Without knowledge about potentially effective responses, it is unlikely they will enact one. We assume that teacher education is already educating these forms of knowledge. Equally important, they must have some degree of selfawareness that they are experiencing stress or emotional reactivity, and they must be able to regulate their reactivity enough to process the situation and then select from what they know to be effective practices an effective response. During highly emotional and stressful experiences, however, it becomes more difficult to access and enact knowledge. Instead, it becomes more likely that coping responses are reflexive and emotionally driven (Klusmann et al., 2008; Mitchell et al., 2019).

Teachers, like any individual faced with highly stressful circumstances, are prone to reactivity rather than responsivity. In a chronically stressful classroom, teachers can quickly become overwhelmed and fall into what Jennings and Greenberg (2009) characterized as the "burnout cascade." The burnout cascade is a self-reinforcing cycle in which teachers develop 
patterns of negative teacher-student interactions that provoke further negative emotions. Consistent with this hypothesis, stress and dissatisfaction with teaching are known to be central factors in teacher attrition (Ingersoll et al., 2018; Ryan et al., 2017). Meditation-based interventions (MBIs) are thought to operate on the precise mechanisms underlying adaptive responses to stress (e.g., self-regulation, self-awareness, emotion regulation; Roeser et al., 2012; Masked, 2022). A nascent area of research investigating the impacts of MBIs on teachers has observed reductions in stress, anxiety, burnout, and depressive symptoms, increases in mindfulness, self-compassion, and well-being, and improvements in standardized observations of teaching (Jennings et al., 2017; Kemeny et al., 2012; Masked, 2022; Roeser et al., 2013). This study extends existing research by asking whether a MBI preventatively implemented during preservice teacher education reduces early career teacher attrition.

\section{Meditation-Based Interventions}

Meditation is an umbrella term that circumscribes many types of contemplative practice, of which mindfulness meditation is perhaps the most ubiquitous. The multifaceted skill of mindfulness is defined as paying attention, on purpose, to present moment experience, with an attitude of non-judgment or acceptance (Kabat-Zinn, 2013). Mindfulness practices are techniques intended to strengthen mindfulness through repetition. For example, during the mindfulness practice of breath awareness one rests attention on the breadth while maintaining a background monitoring awareness. If the mind wanders from the breath, one is instructed to gently bring it back to the breath. The act of resting attention on the breath is said to strengthen the skill of focused attention. The act of monitoring is said to strengthen meta-awareness. The act of gently bringing the mind back without judgment or reactivity is said to strengthen equanimity or acceptance (Dahl et al., 2020). Loving-kindness practices in which one wishes others well and 
compassion practices in which one recognizes others' suffering and wishes that their suffering be alleviated are also frequent components in MBIs (i.e., "connection practices"; Dahl et al., 2020; Hirshberg et al., 2018). These forms of practice emphasize strengthening prosocial dispositions like patience, kindness, and generosity that may also be implicated in teaching.

There is now a large body of evidence that MBIs improve mental health while increasing self-regulation and well-being (e.g., Goldberg et al., 2021). MBI research with teachers has found positive effects on mindfulness, stress, burnout, anxiety, depression, and well-being (e.g., Jennings et al., 2017; Roeser et al., 2013; Masked for review, 2022a). Scholars have also suggested, and some data indicate, that MBIs may improve teacher classroom practices (Jennings et al., 2017; Masked for review, 2020), though the evidence for this is not yet firmly established.

Mindfulness can be understood as an adaptive form of self-regulation. Adaptive forms of self-regulation are associated with the maintenance of high-quality student-teacher interactions (Klusmann et al., 2008). Classroom management, one of the main stressors identified by early career teachers (Greenberg, Putnam, \& Walsh, 2014), and instructional practices improve as teachers demonstrate greater self-regulation and sensitivity to context, and less reactivity (Baumert \& Kunter, 2013; Klusmann et al., 2008). MBI researchers have posited that by increasing awareness of internal and external experience while cultivating the ability to accept present-moment experience without unnecessary reactivity (i.e., Monitor and Acceptance Theory; Lindsay \& Creswell, 2017), teachers and other individuals in high-stress professions may be better resourced to adapt to the challenges of their profession (Roeser et al., 2013).

Connection practices intended to strengthen prosocial skills and attitudes such as empathy, kindness, gratitude, and compassion may also help teachers navigate occupational challenges. In particular, connection skills may be salient to interpersonal and emotional 
dimensions of teaching, as they form the basis of warm, supportive, and caring relationships. We reasoned that preventatively training PSTs in mindfulness and connection practices might provide tools that help them adapt to the complexities of the profession, increasing career longevity.

\section{The Current Study}

Although MBIs appear well situated to address a number of the identified individuallevel causes of early career attrition, to our knowledge, no research has yet evaluated this possibility. We address this gap in the literature by testing whether a mindfulness and connection intervention implemented during undergraduate PST education resulted in reduced rates of attrition four-years later at the critical year three juncture of professional teaching. We also advance the field of teacher education methodologically by preregistering the study design and measures (Masked link), employing a causal design (i.e., a cluster randomized controlled trial), applying multiple robustness tests to the data, and contextualizing the results in a benefit-cost analysis (BCA). We hypothesized that assignment to the intervention during PST education would predict significantly greater odds of persistence in teaching three-years into participants' professional teaching careers.

\section{Method}

\section{Participants}

Participants $(n=98)$ were recruited from an undergraduate elementary PST education program at a large research university in the United States. The elementary education program consists of four licensing areas: Early Childhood - English as a second language; Middle childhood/Early adolescent - English as second language; Middle childhood/Early adolescent Special education; and Middle childhood/Early adolescent - Content focused minor. Licensing 
areas operate as cohorts, with approximately 24 students moving through the two-year course sequence in unison as a cohort. The two-year sequence includes coursework as well as clinical work, and concludes with an undergraduate degree in education and appropriate teaching licensure, assuming all licensure requirements have been met.

Two cohorts from each type of licensing area participated in the study (i.e., eight cohorts in total). Approximately fifty-six percent of eligible PSTs from these eight cohorts consented to become research participants. Participants were $96.94 \%$ female $(n=95)$ and $85.71 \%$ Caucasian/White $(n=84)$. About $5 \%$ of participants self-reported as Hispanic $(n=5), 4.08 \%$ as Asian (n=4), another $3.06 \%$ as African American $(n=3)$, with two self-reporting as mixed or other race $(2.04 \%)$. The average age was 21.99 years old $(S D=0.68)$. The sample's race/ethnicity and gender distributions were representative of the demographics of the PST program involved in this research (i.e., around 94\% female and $85 \%$ White). Two participants from each group graduated from the PST education program but never entered into professional teaching, reducing the analytical sample to $n=94$ (39 control; 55 intervention).

In prior publications that reported on post-intervention and six-month follow-up outcomes (Masked for review, 2020; 2022b; Figure 1), we removed one control cohort $(n=10)$ from analyses because an unknown number of this cohort's PSTs violated a study protocol against control participants engaging in a MBI. In primary analyses we report on all randomly assigned participants who entered into professional teaching (i.e., intention-to-treat sample; $\mathrm{k}=8$; $N=94 ; n=39$ Control; $n=55$ Intervention). In sensitivity analyses, we report on the reduced sample after removing this cohort $n=88(\mathrm{k}=7 ; n=31$ Control; $n=57$ Intervention). All data presented in this manuscript is publicly available at osf.io/masked.

\{Figure 1\} 


\section{Power Analysis}

Study sample size was based on an a priori power analysis indicating that in order to detect MBI effects of Cohen's $d \geq 0.60$ on mindfulness and race bias (Kang et al., 2014; Roeser et al., 2013), two of the primary outcomes from the trial, a sample of $n=100$ would be sufficient, assuming $\alpha=0.05$, and power $(1-\beta$ error probability $)=0.80$.

\section{Study Design}

This study was designed as a longitudinal cluster randomized controlled trial conducted over the final year of undergraduate preservice teacher education, with three years of follow-up post-PST program graduation. Primary outcomes from the final year of PST education included mindfulness, race bias, and teaching observation scores (see Masked, 2020; 2022). The primary endpoint of this study was career persistence assessed three-years after graduating from the program (i.e., four years after random assignment).

Operating under the assumption that MBI training integrated within PST education would produce superior outcomes, the intervention was designed to be integrated into extant PST education to the greatest degree possible. Faculty in the elementary education program unanimously voted to allow 30-minutes of the weekly two-and-a-half-hour cohort seminar class to be used for the MBI for cohorts assigned to treatment during the first semester of the final year in the program (i.e., first semester senior year). Depending on the schedule of the treatment cohort, the 30-minutes of seminar time allotted to the MBI occurred at the beginning or end of weekly seminar time. An additional 60-minutes of the MBI was conducted contiguously. All intervention cohort students participated in the 30-minutes of the MBI held during seminar time. All PSTs were able to participate in the additional 60-minutes of intervention held contiguously, but only research enrolled participants were expected to do so. During the final semester of the 
PST program, intervention cohorts participated in 15-20 minute "booster sessions" once per month during cohort seminar time.

Over four consecutive semesters (Fall 2015 - Spring 2017), two cohorts from each of the four licensure areas in Elementary Education were recruited into the study. In total, eight cohorts of PSTs were involved in this research (Figure 1). All participants were placed in classrooms (i.e., practicum) during the first semester of study participation. In the second semester of participation (i.e., final semester of the PST program), participants were placed in schools full time as student teachers, including a period of two to four-weeks in which they took over all classroom teaching responsibilities (i.e., "lead weeks"). Study assessments were conducted before random assignment (baseline), at the end of the intervention and first semester of participation (post-test), at the end of the second semester of participation just before graduation (approximately 6-month follow-up), and each October through December for three years after graduation (long-term follow-ups one through three). For long-term follow-ups, we sent a survey link via email asking about employment, stress, burnout and occupational well-being. Here we report on the primary endpoint of the long-term follow-up assessments - whether participants were teaching at the final long-term follow-up three-years into their professional careers.

We block randomized by licensure track so that, at study end, one cohort from each licensure track was assigned to intervention and the other to control. By block randomizing on licensing area, we controlled for the possibility that licensure areas enrolled PSTs with different characteristics, systematically affected PSTs differently, or systematically produced different occupational outcomes that might bias estimates. For example, it is known that Special Education teachers have higher rates of career attrition than other certification areas (Billingsley \& Bettini, 2019). Block randomizing by licensure area ensured that one Dual certification (i.e., 
Early Education and Special Education) licensing cohort was assigned to intervention and the other to control

This design did not necessarily account for possible time effects. That is, it is possible that the timing at which cohorts enrolled into the study was associated with exogenous factors that could bias estimates of persistence. The final long-term follow-up assessment for the last two cohorts that enrolled in Fall 2017 occurred in October - December of 2020, the first full COVID-19 pandemic school year. If both of these cohorts were assigned to the same condition, for example, it is possible that estimates of persistence would be biased by pandemic effects on career decisions. Although the study did not by design control for time effects, the block random number sequence generated prior to study onset stipulated that group assignment was balanced across time (i.e., each semester the same number of cohorts were assigned to treatment and control). Because an equal number of cohorts were assigned to treatment and control at each study phase, any external events that may have affected PSTs impacted the same number of intervention and control cohorts.

Participants were kept blind to their cohort assignment until after pre-testing was completed. However, because of the cohort structure of the PST program, it is possible that cohort dynamics led to individuals from within a cohort being more or less likely to enroll in the study. Some evidence suggests that this was the case. Rates of enrollment differed between the cohort with the highest (84\%) and lowest (18.2\%) rates of enrollment. Differential rates of enrollment are a particular concern for the Dual certification (i.e., Early Education and Special Education) cohorts because Special Education teachers are known to attrite at higher rates than other teachers. The intervention group Dual certification cohort was three times as large as the control Dual certification cohort ( $n=12$ versus $n=4)$, suggesting that if differential rates of 
enrollment biased estimates, a downward bias of intervention effects would be expected.

Participants were compensated $\$ 145$ for completing pre-, post-, and the initial follow-up assessments. An additional \$15 was provided upon completion of each longitudinal follow-up (maximum of \$190). Masked Institutional Review Board approved all materials and procedures. Data and code used in this manuscript are available on osf.io (Masked link).

\section{Measures}

The primary outcome, coded as $0=$ No $/ 1=$ Yes, was whether participants were teaching at the year three long-term follow-up. We used self-reported employment on the year three survey and public employment data from the Masked Department of Public Instruction to confirm selfreported data and populate employment data for year three survey non-responders. We were able to collect employment status on all participants (98/98) at the year one and year three longitudinal surveys.

Intervention implementation fidelity was assessed in multiple ways. The same three instructors co-taught all four implementations to ensure consistency. The curriculum was manualized. Each week instructors were provided with a checklist of the core content intended for that session. These checklists were compared post-study. The same guided audio meditations were provided to participants in all of the implementations, along with the same recommended daily practice instructions. Weekly reports on outside of class meditation practice were collected from intervention participants. Attendance at weekly sessions as well as the two extended practice intensives was also recorded.

\section{Data Analysis}

Using Welch's t-tests and chi-square tests, we first checked for balance between the groups on the wide range of observed variables collected at pre-test (Supplemental Materials 
Table S1). Using a Fisher's exact test, we compared rates of entry into teaching between the groups. Participants who never entered into teaching ( $n=4$; control 2, intervention 2$)$ could not attrite and were removed from subsequent analyses (analytical sample $n=94$ ). Persistence rate estimates could also be biased by differential rates of school turnover between the groups. This concern is particularly salient for benefit-cost estimates because the left school incurs the same hiring costs whether a teacher leaves the profession or goes to another school. Using a Fisher's exact test, we compared turnover rates between the groups. Finally, urban schools serving high proportions of low-income students have consistently higher rates of turnover and attrition than suburban schools (Boyd et al., 2011). Therefore, it was important to examine patterns of employment at year one. We constructed a three-level categorical variable (school type) to reflect the type of school participants worked in in their first year of professional teaching. Urban schools serving a high proportion of free and reduced lunch program students were the reference category. Relatively affluent suburban schools and a combination of rural, parochial, foreign and other types of schools were combined to make up the second and third categories, respectively. In addition to testing for group differences, we also control for this variable in subsequent attrition/persistence analyses.

Multiple modeling strategies were used to investigate the MBI's effect on career persistence at year three as well as the robustness of the observed effects. We first estimated a generalized random-intercept hierarchal linear model (HLM) in which participants were nested within cohort and persistence at year three was regressed onto group (control/intervention) and the school type covariate. This approach is appropriate due to random assignment occurring at the cohort level and accounts for dependence among the observations within cluster (i.e., cohorts). Although there is debate regarding the minimum number of level-2 units required for 
HLM, not applying HLM may inflate type I error by underestimating standard errors (Huang, 2018). The mixed HLM can be written as:

$$
\mathrm{Y}_{\mathrm{ij}}=\gamma_{00}+\gamma_{01} * \text { GROUP }_{\mathrm{i}}+\gamma_{10} * \text { Y1. Schooltype } \mathrm{ij}_{\mathrm{j}}+\mathrm{u}_{0 \mathrm{j}}+\mathrm{r}_{\mathrm{ij}}
$$

where $Y_{i j}$ is the probability of participant $\mathrm{i}$ in cohort $\mathrm{j}$ persisting at year three, $\gamma_{00}$ reflects the average persistence rate in the control condition, $\gamma_{01}$ represents the effect of assignment to the intervention $(0=$ control; $1=$ intervention $), \gamma_{10}$ is the effect of year one school type, with random effects $u_{0 j}$ (level-2 [cohort] intercept residual) and $r_{i j}$ (level-1 [participant] residual).

This model produced a singularity warning, suggesting that the random effect structure was too complex for the data and raising concerns about the validity of model parameters. However, we modeled the simplest random effect structure. One explanation for singularity is that the clustering (i.e., cohorts) explained virtually no outcome variance. This conclusion appears reasonable when looking at the lack of variability in persistence rates by intervention cohort. Intervention cohort persistence rates were 100\%, 89.5\%,100\%, and 100\% (Figure 2).

\section{\{Figure 2\}}

Although the data suggest that the clustering may be ignorable, it remains possible that doing so could bias estimates. Bayesian HLM estimation can avoid singularity because posterior estimates are always hypothetically possible and have the added benefit of providing stable estimates for clusters with smaller sample sizes (Hox et al., 2012). We therefore next estimated the equivalent HLM in a Bayesian framework. Informative priors were calculated based on evidence that approximately $22 \%$ of new teachers attrite by year three and $90 \%$ confidence that less than $90 \%$ of new teachers would still be teaching after three years (Goldhaber \& Theobald, 2022; Ingersoll et al., 2018). The Bayesian HLM can be written identically to the above, but in the Bayesian framework results can be interpreted as the likelihood (or probability) of the model, 
and the random intercept $u_{0 j}$ is thought of as a prior distribution informed by the data. The high density interval (HDI; aka credible interval) takes the place of the frequentist confidence interval. All points within the HDI have a higher probability density than points outside of it. The region of practical equivalence (ROPE) is the percentage of parameter estimates that fall within a specified HDI and can be thought of as an equivalence test. Kruschke (2018) suggested using this combination of no parameter estimates from the HDI falling within the ROPE as the null hypothesis rejection rule. Using a 95\% HDI, when no samples fall within the ROPE, such a result indicates that there is a $95 \%$ probability of no equivalence between the parameter estimates and the null hypothesis of no difference. R package references can be found in Supplemental Materials.

In addition to standard and Bayesian HLM, we modeled the data in two fixed effects frameworks. As noted, it is plausible that the clustering is ignorable. Firth's bias-reduced likelihood regression adjusts for bias in logistic regression with rare outcome events such as attrition in these data (Firth, 1993). This model that can be written as:

$$
Y_{i}=1 / e^{-\left(\beta^{0}+\beta^{1} * \mathrm{GROUP}+\beta_{2} * Y 1 . S c h o o l t y p e\right)}
$$

where $Y_{i}$ is the likelihood participant i persisting at year $3, \beta^{0}$ the persistence rate for the control condition, $\beta^{1}$, the effect of interest, is the effect of assignment to the intervention, and $\beta^{2}$ the effect of year one school type. For details on the penalty in Firth's regression, see Firth (1993).

Cluster robust standard errors (i.e., sandwich estimators) are another approach to account for clustering (e.g., the randomization unit is at the cluster not the individual-level; McNeish \& Stapleton, 2016). More recently, methodologists have suggested bootstrapped and wild bootstrapped cluster robust standard errors in hierarchal data with small numbers of clusters (Deen \& de Rooij, 2020; MacKinnon \& Webb, 2018). We attempted to estimate a final 
generalized linear model that applied bootstrapped cluster robust standard errors to the randomization cluster (i.e., cohort) and controlled for study wave (enrollment timing) following the procedure described by Deen and de Rooij (2020). Including a fixed effect of enrollment wave in theory allowed us to answer the question of whether, after removing enrollment timing effects, adjusting for clustering within cohorts, and controlling for school type at year one, there was a group difference in persistence. This model can be written as:

$$
Y_{i}=1 /\left(1+e^{-\left(\beta^{0}+\beta^{1} * \mathrm{GROUP}+\beta^{2} * Y 1 . S c h o o l t y p e+\beta^{3} * \text { Enrollmentwave }\right)}\right)
$$

where, as above $\mathrm{Y}_{\mathrm{i}}$ is the likelihood participant $\mathrm{i}$ persisting at year $3, \beta^{0}$ the persistence rate for the control condition, $\beta^{1}$ the effect of assignment to the intervention, and $\beta^{2}$ is the effect of year one school type, and $\beta^{3}$ is the effect of enrollment timing. This model produced warnings that a large number of bootstrap samples (2919) returned at least one missing value and fitted probabilities of zero or one occurred, leading to uninterpretable model estimates that we do not report. Estimation of these methods is known to breakdown when either the outcome is close to perfectly discriminated by the explanatory variables or there is little variability in the outcome (Deen \& de Rooij, 2020). In these data, both are potential concerns. Nearly all intervention participants persisted at year three and in three out of four waves, $100 \%$ of intervention participants persisted.

Due to concern about statistical inferences from asymptotic $p$-values in relatively small sample sizes, we also estimated a Fisher's exact test comparing attrition rates between the groups. Fisher's exact test uses the true distribution rather than assumptions based on a large sample asymptotic distribution (Bind \& Rubin, 2020). In sensitivity analyses, we re-estimated each of the above approaches with the impacted control cohort removed. Further details on 
model specification, diagnostics, and R package references are provided in Supplemental Materials.

Benefit-Cost Analysis. Time is precious and in short supply in many PST education programs. PST educators frequently feel that the time allotted is inadequate to meet current standards of learning and clinical experience. The perception of an opportunity cost in MBIs, in the form of taking time away from tradition PST educational experiences, may render MBIs de facto poorly received. We assume that in order for research evidence to be taken up and put into practice by teacher educators, it must reflect the realities of PST programs and of professional teaching. While prevention strategies may be a strong incentive for PSTs who are aware of high burnout rates, our goal for the BCA was to provide an additional reference point for teacher educators and policymakers who might consider the role and relevance of MBIs to teacher education. Thus, BCA estimates are based on assumptions that provide credible estimates of the lower and upper bounds of costs and benefits (i.e., preventive savings) associated with the MBI implemented in this research, not ideal returns in ideal circumstances.

Following Society for Prevention Research standards for BCAs (Crowley et al., 2018), intervention costs were estimated with the ingredients method. The ingredients method, in which all costs associated with program implementation are individually calculated and summed, provides a comprehensive cost estimate (Belfield et al., 2018). Ingredient costs were based on CostOut ${ }^{\circledR}$ (Hollands et al., 2015) estimates for items populated within the CostOut $®$ program, actual costs incurred for items not populated within $\operatorname{CostOut} \AA$, and in the case of intervention instructor training costs, the projected costs to undertake the minimal amount of meditation and meditation teacher training required to teach the intervention. All costs and benefits are estimated in inflation adjusted 2022 dollars. Whenever possible, costs were based on estimates from the 
region of the United States where this research occurred.

After summing ingredients for lower and upper bound cost estimates, the marginal per participant costs were calculated by dividing the lower and upper cost bounds (CB) by the intention-to-treat sample (ITT; intervention $n=57$ ). In line with a conservative BCA approach, this approach overestimates the marginal per person cost because the intervention was provided to all PSTs in intervention cohorts ( $n=84$; up to 25 per intervention cohort), not only the PSTs in intervention cohorts who enrolled as research participants (i.e., ITT sample). Per cohort marginal costs were calculated by dividing the lower and upper bound cost estimates by four (i.e., the number of intervention cohorts).

Cost estimates are incremental to PST education costs. That is, the intervention was conducted as a partial add-on to standard PST education with one-third of the training occurring within existing PST education seminar time and the rest contiguous to it. We therefore assume no costs associated with this research for the control condition, which received teacher education as usual. However, although the intervention was partially integrated into existing PST education and therefore some implementation costs were partially or fully accounted for by existing PST education (e.g., room rental fees, administrator fees), to ensure our BCA estimates cover the credible range of potential costs, in upper cost bound estimates we included potential future costs. Intervention lower cost bound estimates included all intervention-related costs accrued during this study (i.e., actual costs).

There are additional reasons costs estimates are conservative (i.e., high). To ensure adequate instructor coverage at each intervention session, all intervention groups were taught by three instructors. Cost estimates therefore included estimated intervention instructor-training costs and payment fees for three instructors. In practice, many similar MBIs are taught by only 
one instructor, potentially reducing instructor training costs and payments by two-thirds. In addition, none of the estimated instructor-training costs were assumed by this research. Instructors were selected because they already possessed the requisite training and experience. In many conceivable future implementations, it is likely that intervention teacher selection will occur based on existing qualifications. We nevertheless included instructor training costs in both lower and upper cost bound estimates because it is possible in-depth instructor training could be required. In addition, once an intervention instructor is trained, training costs are distributed across all future interventions they will teach. We divided estimated instructor training costs by four because there were four intervention implementations in this research, but once trained an instructor could implement the intervention 10, 20, or 100 times over the course of many years, significantly reducing the marginal per participant and per implementation instructor and overall costs.

Benefits are the estimated preventive savings accrued by school districts that hired a teacher who persisted rather than one who would otherwise have been predicted to have left by year three. The observed year three attrition rate in the control group (23.08\%) was used as the expected attrition rate for the intervention group (i.e., population attrition rate). This rate of attrition is consistent with a number of estimates of teacher attrition within the first years of professional teaching (Goldhaber \& Theobald, 2022; Gray \& Taie, 2015; Guthery \& Bailes, 2022; Ingersoll et al., 2018). The expected attrition count for the intervention group was the intervention group ITT sample $n=55$ times the control group attrition rate.

Three types of attrition costs were computed separately for each group. Actual or observed attrition cost lower and upper bounds were respectively estimated by multiplying the observed group attrition counts at study endpoint by Shockley et al.'s (2006; \$6,838.79 in 2022 
dollars) and Barnes et al.'s (2007; \$22,631.06 in 2022 dollars) teacher replacement cost estimates. The point estimate is the average of the resulting bounds. These estimates provide poor group attrition cost comparisons because they do not account for the differences in group sample sizes.

Expected attrition costs for the control group are the observed attrition costs; We assume the attrition rate in the control group is the untreated population attrition rate. Expected attrition costs in the intervention group are the multiple of the lower and upper replacement cost estimates by the expected attrition count in the intervention group (i.e., control group attrition rate times the intervention group sample size). The result are comparable estimates of expected attrition costs in the intervention and teacher education as usual control groups. For the simulated analyses of equal group sample size of 100, the same steps were followed but extrapolated for each group based on a sample of 100 . One hundred was selected because it is the maximum number of PSTs that could have been treated within the design of this study without adding costs (i.e., 25 PSTs per intervention implementation).

Two estimates of intervention benefit were calculated (for the intervention group only). Benefits based on the ITT sample were computed by subtracting the observed attrition costs from the expected attrition costs. This estimate represents preventive savings resulting from fewer than expected (based on control group attrition rates) intervention teachers leaving teaching by year three. Benefits based on simulated group sample sizes of 100 subtracted from the predicted control group attrition costs the predicted attrition costs in the intervention group. Lower and upper bounds as well as point estimates were computed again using Shockley et al.'s (2006) and Barnes et al.'s (2007) teacher replacement cost estimates.

The net present value (NPV) is the difference between the benefits (i.e., predicted 
attrition costs minus the observed attrition costs) minus the cost of the intervention. The ITT NPV is the ITT sample benefit estimate minus the ITT sample observed attrition costs. The NPV per 100 is the predicted benefits in a sample of 100 minus the predicted intervention group attrition costs in a sample of 100 . The lower NPV bound, computed by subtracting the lower bound of benefit from the upper bound of intervention costs (i.e., when all potential costs of a future implementation were summed) is conservative. The upper NPV bound, computed by subtracting the lower intervention cost bound from the upper benefit bound, is less conservative. This approach produces a wider boundary interval, providing a credible range for the NPV. The benefit-cost ratio is calculated as the total benefits divided by the actual cost of the intervention. For benefit-cost ratio bounds, we used the actual costs incurred.

\section{Intervention}

A detailed description of the intervention as well as a sample lesson can be found in Supplemental Materials. The 9-week training was based on Mindfulness-Based Stress Reduction (Kabat-Zinn, 1982) and a traditional Tibetan Buddhist structure to mind training. Over the course of one semester, the intervention consisted of weekly 1.5-hour classes along with two 4-hour intensive practice days (21.5 hours total). During the following semester, intervention cohorts followed a prescribed sequence of 15-minute weekly practices implemented during seminar. Mindfulness practices included breath awareness, body scan (scanning of body sensations), sound practice (using sounds as the anchor for attention), walking meditation, and mindful movement. Connection practices included generating feelings of warmth and well-wishing for oneself and others and contemplation on the caring intention to teach. Intervention participants were asked to spend 10-20 minutes each day on a mindfulness or connection practice. The three intervention instructors were consistent across waves. Each instructor had extensive classroom 
and mindfulness teaching ( $>10$ and 5 years, respectively) and meditation practice experience $(>10$ years $)$

\section{Results}

On the wide range of measures collected at baseline, we observed no evidence for group differences (See Supplemental Materials Table S1). There was no evidence that year one school type differed between the groups (Fisher's exact test $p=0.590$ ). On the subset of participants for whom we have year one and year three school data, there was no evidence that rates of turnover (changing schools/districts but remaining in teaching) were different between the groups (Fisher's exact test $p=0.265)$. Turnover was descriptively higher in the control group (control 54\%, 19/35; intervention 40\%, 19/48).

\section{Implementation Fidelity}

Approximately $68 \%$ of (39/57) of intervention participants reached prescribed criteria for full class attendance (i.e., 8/9 classes and both intensive sessions). Eighty-eight percent of intervention participants attended at least one extended practice session. On average, participants reported 13.94 minutes of meditation practice per day $(S D=9.47)$. Recommended daily practice began at 5 minutes per day and increased to 20 minutes per day by the end of the main intervention semester. Over $95 \%$ of intervention content was delivered during the intended session, and there was near total consistency ( $>95 \%)$ between the waves. All but one cohort, due to external disruptions, adhered to the weekly practice schedule during the second semester.

\section{Persistence in Teaching}

Of the participants who entered into teaching $(94 / 98 ; 95.92 \%)$ after graduating from the PST program, nine out of 39 control (23.08\%) and two out of 55 intervention (3.36\%) PSTs had left by year three. In HLM, the intervention group's odds of persisting at year three were 7.72 
[95\% CI: $1.55,38.50]$ times greater than control participants $(p=.013)$. Year one school characteristics did not significantly predict attrition at year three, but working in urban schools serving high proportions of low-income students was associated with lower odds of persisting at year three than working in suburban or other types (e.g., rural, parochial) of schools.

In Bayesian HLM, the intervention group's odds of persisting at year three were 4.44 times greater than control participants, $95 \%$ HDI $[1.78,11.01]$, with $0 \%$ of samples inside the region of practical equivalence (ROPE). These results can be interpreted as $95 \%$ probability that parameter estimates fall completely outside of the null hypothesis that group rates of persistence at year three do not differ. Working in suburban and other types of schools in year one were associated with greater odds of persistence at year three (reaching Bayesian threshold for rejecting the null) than working in urban schools in year one.

In Firth's bias reduced likelihood regression, the odds of intervention participants persisting at year three were 6.23 [95\% CI: 1.64, 34.07] times greater than control participants $(p=.006)$. A similar pattern regarding year one school type was observed. In a Fisher's exact test, assignment to the intervention was associated with 7.78 [95\% CI: 1.47, 78.52] times the odds of persisting in teaching at year three $(p=0.007)$.

\section{\{Table 1\}}

\section{Sensitivity Analyses}

After removing the affected control cohort, the intervention group's odds of persisting at year three were significantly greater at a large magnitude than the control group across all analytic approaches. Odds ratios of intervention compared to control group likelihood of still teaching at year three ranged from 4.33 to 8.30 . In Bayesian HLM, $0.0 \%$ of the credible intervals were within the ROPE. 


\section{Benefit-Cost Analysis}

The ingredients list is provided in Table 2 and BCA results in Table 3 where we provide an estimate with lower and upper cost bounds in the parenthesis (CB). In ITT analyses, the intervention resulted in an estimated average benefit (i.e., savings to school districts over the first three years of participants' careers) of $\$ 157,516$ (CB: $\$ 86,784, \$ 287,188$ ) for a per participant benefit of $\$ 2,763.44$ (CB: $\$ 1,354.56, \$ 4,244.32$ ). The actual cost of the intervention was $\$ 45,910$ or $\$ 805.44$ per participant. The NPV of $\$ 128,046$ (CB: $\$ 27,844, \$ 228,248)$ or $\$ 2,246.42$ (CB: $\$ 488.49, \$ 4,004.35)$ per participant results in a benefit-cost ratio of 3.43 (CB: $1.59,5.27)$. In other words, for every dollar invested in the intervention during PST education, districts saved between $\$ 1.59$ and $\$ 5.27$ in expected replacement teacher recruitment, hiring, and training costs over the study period. In a balanced design with 100 participants per group, the predicted per participant NPV and benefit-cost ratio were \$2,911.46 (CB: \$1,329.71, \$4,493.21) and 6.34 (CB: $2.90,9.79)$, respectively.

\section{\{Table 2\}}

\section{$\{$ Table 3\}}

\section{Discussion}

Early career teacher attrition disrupts school continuity, precludes many of those who leave from reaching their potential effectiveness as teachers, and drains limited economic resources from school districts. Moreover, because urban and high-poverty schools experience greater turnover, teacher attrition may contribute to inequitable educational opportunities for minoritized students. Today, a majority of teachers are considering leaving the profession early and fewer potential teachers are considering entering the profession (Walker, 2022). We report that assignment to a nine-week mindfulness and connection intervention during undergraduate 
PST education increased the odds of persisting in teaching at the crucial year three juncture by 4.44 to 7.78 times relative to control group teachers who received the same PST education but not the intervention. This effect was not the result of differences in the types of schools intervention and control participants worked in as in-service teachers after graduating from the PST program or higher rates of school change (i.e., turnover) during professional teaching in the intervention group.

The significantly greater odds of persistence among intervention PSTs were also not the result of unusually high attrition rates in the teacher education as usual control group. Consistent with many estimates of early career attrition, $23.08 \%$ of the participants in the control group who had entered professional teaching upon graduating from the PST program had left by year three. Rather, the observed intervention effects were the result of significantly lower than expected rates of attrition in the intervention group. Of the 55 intervention group participants who entered into professional teaching, only two had left in their first three years teaching $(3.64 \%)$. This three-year rate of attrition is about half of the yearly teacher attrition rate (Goldhaber \& Theobald, 2022; Ingersoll et al., 2018).

In three of the four intervention cohorts, all PSTs who entered into teaching were still teaching after three years. The lowest persistence rate among an intervention cohort $(89.47 \%)$ was about 12 percentage points higher than the overall control group persistence rate. Whether comparing average intervention versus teacher education as usual rates of attrition, attrition rates between the same type of teacher licensure track, or attrition rates between treatment and control cohorts that enrolled in the study at the same time, intervention cohort rates of attrition were substantially lower that the control group attrition rates and expected attrition rates based on available estimates (see Figure 2). Surprisingly, the exception was in the dual certification 
cohorts (i.e., Early education and Special Education) - a category of teachers known to have high rates of attrition. In both the intervention and control Special Education cohorts, all PSTs who entered into teaching were still teaching at year three. However, the dual certification control cohort was by the far the smallest in the study $(n=4)$, raising questions about the representativeness of the small proportion of PSTs in that cohort (about 18\%) who chose to participate in the research.

Large magnitude, statistically significant effects of the intervention were observed across all of the modeling strategies employed. The consistency of the estimated intervention effect, nearly identical in models assuming an asymptotic large sample distribution and methods utilizing the observed distribution, adds confidence that the observed effect was not an artifact of modeling approach. The smallest Odds ratio estimate of 4.44, still large in magnitude, was estimated in a Bayesian HLM using informative priors that were restrictive relative to the observed data.

A key question emerging from these results is through what mechanisms the intervention appears to have promoted substantially greater early career persistence. Unfortunately, owing to insufficient power for statistical mediation analyses and high levels of missingness on the longitudinal self-report surveys, these data are not well suited to empirically identifying causal mechanisms. Increased persistence following the MBI is consistent with the theoretical framework motivating the study; that MBIs integrated into undergraduate PST education build skills and dispositions that support transitioning into professional teaching. As reviewed in the introduction, prior theoretical models have posited that a primary mechanism of benefit for teachers is reduced stress and burnout (e.g., Jennings \& Greenberg, 2009; Roeser et al., 2012). Evidence from research on MBIs with in-service teachers supports this theory (Jennings et al., 
2017; Kemeny et al., 2012; Roeser et al., 2013), but it is less clear that MBIs during PST education reduce stress (e.g., Hue \& Lau, 2015), perhaps because PSTs are not experiencing the same levels of distress as in-service teachers (Kush et al., 2022; Masked 2023). In the larger study from which these long-term follow-up data were drawn, the intervention group reported significant post-intervention improvements in mindfulness but not in stress or burnout, while showing significant gains on an observation of actual classroom instruction just before graduating from the PST program (Masked, 2020). Vagi et al. (2019) reported that PSTs whose instruction was rated more highly upon graduation were more likely to persist.

Taken together, one interpretation of these findings is that integrating the MBI within teacher education helped PSTs learn to become better teachers (i.e., greater gains on teaching observations) while strengthening skills and dispositions that are theoretically supportive during teaching (e.g., mindfulness). This interpretation lends itself to the mediational hypothesis that reduced attrition was the result of increased instructional as well as other teaching-relevant competencies upon entry into professional teaching. Future research designed and powered to test these pathways, as well as other related questions is needed. For example, it will be important for future research to clarify whether effects were the result of the MBI alone, or a synergy between the MBI and, in this case, its partial integration into teacher education. The answer to this question has important implications for optimal strategies for involving MBI content in teacher education.

Following Society for Prevention Research standards for benefit-cost analyses, we estimated that the MBI-related reductions in attrition saved districts that hired PSTs assigned to the intervention $\$ 157,516$ in replacement teacher recruitment, hiring and training costs over the three years of the study, after accounting for the costs of the intervention. In parts of the country 
with low teacher replacement costs, we estimate that each intervention teacher hired saved the hiring district $\$ 1,354.56$ over the study period. In higher cost areas, we estimated that districts saved $\$ 4,244.32$ per intervention teacher hired. In terms of return on investment, every dollar invested in the intervention resulted in an average savings to districts of $\$ 3.34$. Extrapolating to a balanced sample of 100 PSTs in each group, every dollar invested in the intervention would save districts $\$ 6.34$, or approximately $\$ 3,000$ per teacher. As noted previously, these estimates are conservative.

There are several important reasons, outlined below, to be cautious about drawing broad generalizations based on these data. Nevertheless, it is important to contextualize the observed results within the large numbers of teachers hired annually, in part the consequence of attrition, and the challenges in many locales of hiring qualified teachers (Peyton et al., 2021; Wiggan et al., 2021). If the US Department of Education's (2021) predictions for the number of teachers hired for the 2022-2023 school year $(357,000)$ was accurate and half of these new teachers received the MBI studied, our lower and higher ITT bound (See Table 3) three-year savings estimates would total $\$ 241,788,960$ and $\$ 757,648,605$, respectively. Even if the true population effect of the intervention has been overestimated, the critical point is that small reductions in early career attrition can result in significant benefits. At the lower bound teacher replacement estimate, the BCR is zero (i.e., no benefit to the MBI costs) at an eight percent reduction in the attrition rate (per 100 new teachers) over three years. At the higher bound teacher replacement estimate, the BCR is zero at approximately just a two percent reduction in the attrition rate (per 100 new teachers) over three years.

Equally important to the financial savings, students and schools benefit in multiple ways by even small reductions in early career attrition. For example, students of teachers who persist 
benefit from their teacher's accrued on-the-job learning. In addition, lower staff turnover is associated with improved school climate and staff morale, both of which are associated with improved student outcomes (Thapa et al., 2013). This research suggests that rather than viewing MBIs as somehow orthogonal to teacher education, they might more appropriately be viewed as synergistic with, complementary to, or even necessary for optimal teacher education outcomes.

There are several important limitations in this research. First, the sample is relatively small which, combined with the frequency of attrition, makes replicating these results in a larger sample of PSTs essential. Second, this study sampled from a teacher education program at a large research university. As a result, the PSTs involved in this research may differ in important ways from PSTs enrolled at programs in other types of colleges and universities, as well as future teachers coming from non-traditional certification pathways. Although there is no evidence that the effectiveness of MBIs is moderated by the race, gender, or socio-economic status of adult participants, further research is required to understand the impact of MBIs across the varied settings in which teachers are educated and certified. Third, the generalizability of these data may be limited by the relatively homogenous characteristics of the sample. In particular, this sample was more White and more female than PSTs and teachers nationally. It will be important for future research to employ sampling strategies that ensure sufficient numbers of underrepresented groups in teaching (e.g., males and racial and ethnic minorities) to test intervention moderation effects by these factors.

\section{Conclusion}

This study employed a longitudinal cluster randomized controlled trial to test the effect of a MBI provided during undergraduate PST education on persistence in teaching at the critical year three juncture, four years after random assignment. Results suggest that integrating a MBI 
into PST education may be a promising approach to reducing early career attrition, with all its attendant benefits. An important challenge when considering wider implementation of this program is that the benefits are reaped by districts while the costs fall on teacher education programs. As more teachers consider leaving the profession earlier than planned (Walker, 2022) and concerns about teacher mental health grow (Masked, 2023; Pressley, 2021), policy makers and teacher educators alike must concern themselves with promoting teacher mental health in addition to effectiveness, as the two are not unrelated. Rather than viewing MBIs as something foreign to the purposes of teacher education, these data suggest that MBIs designed for teachers may support the core purpose of teacher education - educating effective teachers who stay in the profession. Coupled with robust evidence that MBIs improve mental health and well-being (Goldberg et al., 2021), including among teachers (Jennings et al., 2017; Roeser et al., 2014; Masked for review, 2022a), MBIs may provide affordances not currently offered within standard teacher education that are critical to positive teacher outcomes. 


\section{Figure 1.}

\section{Study Timeline and Overview}

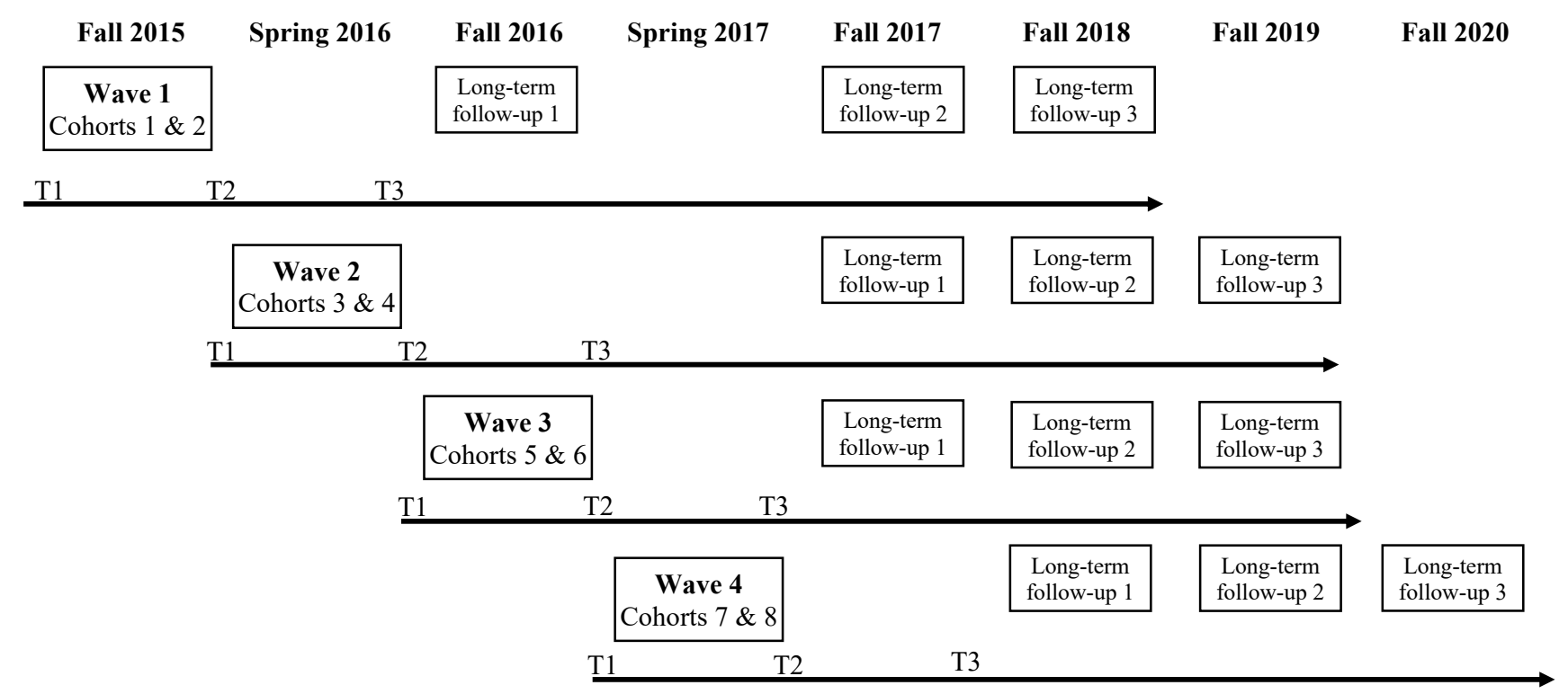

Note. T1: Pre-test prior to random assignment. T2: Post-intervention assessment. T3: Follow-up coinciding with the end of the PST education program and graduation from college. Long-term follow-ups were conducted in November/December each year for three years following graduation from the PST education program. 


\section{Figure 2.}

Persistence Rates in Intervention and Control Cohorts by Study Wave and Cohort Type
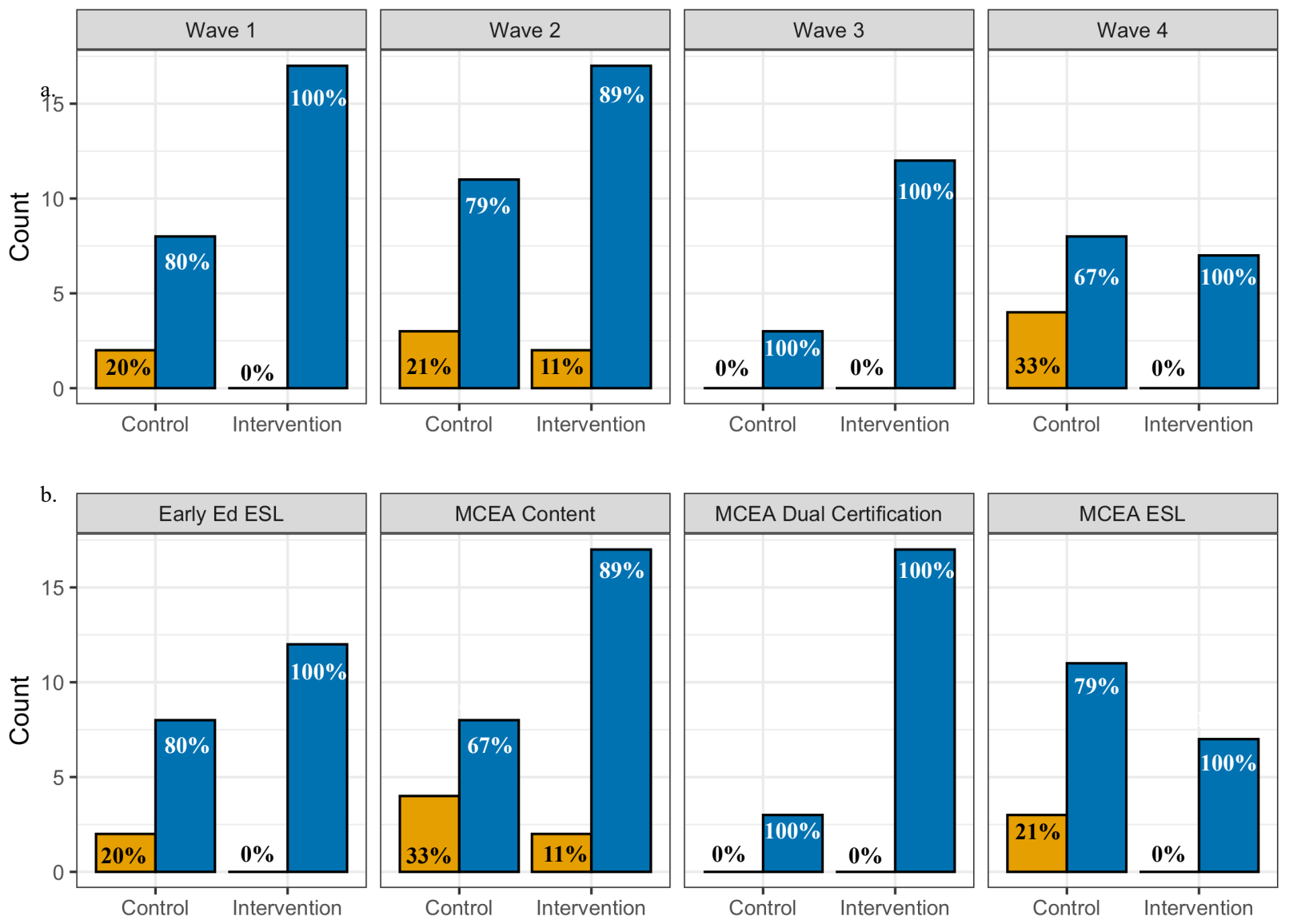

Still Teaching $\square$ No $\square$ Yes

Note. a. Count of control and intervention participants attrition/persistence in teaching at year three by study wave. b. Count of control and intervention participants attrition/persistence in teaching at year three by licensure track. Early Ed ESL: Early Education English as Second Language; MCEA: Middle Childhood Early Adolescence; Content: Content area licensure; Dual Certification: Content and Special Education licensure; ESL: English as Second Language licensure. 
Table 1.

Odds of Persisting in Teaching

\begin{tabular}{|c|c|c|c|c|}
\hline \multirow[t]{2}{*}{ Variable } & \multicolumn{4}{|c|}{ Model } \\
\hline & HLM & Bayesian HLM & Firth's Logistic Regression & Fisher's Exact Test \\
\hline \multirow[t]{2}{*}{ Intervention } & $7.72 *[1.55,38.50]$ & $4.44^{\wedge}[1.78,11.01]$ & $6.23 * *[1.64,34.07]$ & $7.78 * *[1.48,78.54]$ \\
\hline & & $\mathrm{ROPE}=0.0 \%$ & & \\
\hline School Suburban & $1.99[0.34,11.10]$ & $3.21[1.32,7.84]$ & $1.73[0.39,10.29]$ & - \\
\hline School Other & $2.03[0.36,11.40]$ & $3.22[1.32,8.08]$ & $1.76[0.39,10.57]$ & - \\
\hline Sample size & $\mathrm{K}=8, n=94$ & $\mathrm{~K}=8, \mathrm{n}=94$ & $\mathrm{n}=94$ & $\mathrm{n}=94$ \\
\hline \multicolumn{5}{|l|}{ Sensitivity Analyses } \\
\hline \multirow[t]{2}{*}{ Intervention } & $8.30 *[1.54,44.60]$ & $4.33^{\wedge}[1.67,11.04]$ & $4.62 *[1.41,17.34]$ & $5.30 * *[1.31,26.11]$ \\
\hline & & $\mathrm{ROPE}=0.0 \%$ & & \\
\hline School Suburban & $4.80[0.52,44.60]$ & $3.84[1.54,9.67]$ & $3.41[0.64,34.75]$ & - \\
\hline School Other & $4.42[0.47,41.80]$ & $3.78[1.46,9.91]$ & $0.80[0.22,3.01]$ & - \\
\hline Sample size & $\mathrm{K}=7, \mathrm{n}=88$ & $\mathrm{~K}=7, \mathrm{n}=88$ & $\mathrm{n}=88$ & $\mathrm{n}=88$ \\
\hline
\end{tabular}

Note. HLM: Hierarchal linear modeling. CI: Confidence interval. ROPE: Region of practical significance in Bayesian statistics. In

Bayesian HLM, CI stands for credible interval or the $95 \%$ high density interval. The practical significance of an effect can be ascertained by the percentage of the ROPE that fall within the CI, with no samples falling within the rope indicating the null should be rejected. SE: standard error. ${ }^{*} p<.05, * * p<.01, * * * p<.001,{ }^{\wedge}$ reject the null hypothesis in Bayesian models. 
Table 2.

\section{Ingredients Table}

\begin{tabular}{|c|c|c|c|c|c|c|}
\hline \multirow[t]{2}{*}{ Ingredient } & & \multicolumn{5}{|c|}{ Cost (2022 US Dollars) } \\
\hline & Quantity & Unit & Total & Per PST (ITT) & Per PST $(n=100)$ & Per Cohort \\
\hline 1. Art supplies & 4 & 56.85 & 227.40 & 3.99 & 2.27 & 56.85 \\
\hline 2. 3-ring binders & 8 & 3.68 & 29.44 & 0.52 & 0.29 & 7.36 \\
\hline 3. Paperback books & 4 & 6.91 & 27.64 & 0.49 & 0.28 & 6.91 \\
\hline 4. Durable goods (paper) & 4 & 168.80 & 675.20 & 11.85 & 6.75 & 168.80 \\
\hline 5. Dry erase markers & 4 & 8.24 & 32.96 & 0.58 & 0.33 & 8.24 \\
\hline 6. Food & 4 & 259.20 & 960.00 & 18.19 & 18.19 & 259.20 \\
\hline 7. Index cards & 500 & 4.67 & 18.68 & 0.331 & 0.19 & 4.67 \\
\hline 8. Paper copies & 200 & 0.13 & 26.20 & 0.48 & 0.26 & 6.55 \\
\hline 9. Instructor training & 2 & 11,474 & 22,949 & 417.25 & 229.49 & 5,737 \\
\hline 10. Instructor fees & 12 & 1,747 & 20,964 & 367.80 & 209.60 & 5,241 \\
\hline Lower Bound & & & 45,910 & 805.40 & 459.10 & 11,478 \\
\hline \multicolumn{7}{|l|}{ Potential Costs not Incurred } \\
\hline 11. Facilities Rental & 44 & $100 /$ half day & $4,400.00$ & 77.19 & 44.00 & 1,100 \\
\hline 12. Administrator & 112 & 62.23/hour & 6,970 & 122.28 & 69.70 & 1,742 \\
\hline Upper Bound & & & 57,280 & 1,005 & 572.80 & 14,320 \\
\hline
\end{tabular}

Note. Costs are ingredient estimates from CostOut (Hollands et al., 2015) or actual costs incurred, and in the case of instructor

training, the minimal amount of training believed sufficient for MBI implementation fidelity. All costs have been adjusted for inflation to 2022 dollars and whenever possible are regionalized to the area where this research occurred. PST: Preservice teacher. ITT:

Intention-to-treat sample. Per PST (ITT) costs are based on the study sample of $n=55$. Per PST costs are based on the actual number of PSTs who received some of the intervention $(n=84)$ which is larger than the ITT sample because all intervention cohort PSTs, regardless of status as a research participant, received the part of the intervention implemented during mandatory seminar. Per PST 
$(n=100)$ costs reflect maximally efficient estimates because up to this number of participants (i.e., 25 per cohort; 100 total), no additional costs are required. Lower bounds are based on the costs incurred. Upper bounds are based on the cost incurred plus additional costs that might be required in future implementations. 
Table 3.

Intervention Benefits (i.e, preventive savings) and Costs: Intention-to-Treat and Balanced Groups of 100 Participants Analyses

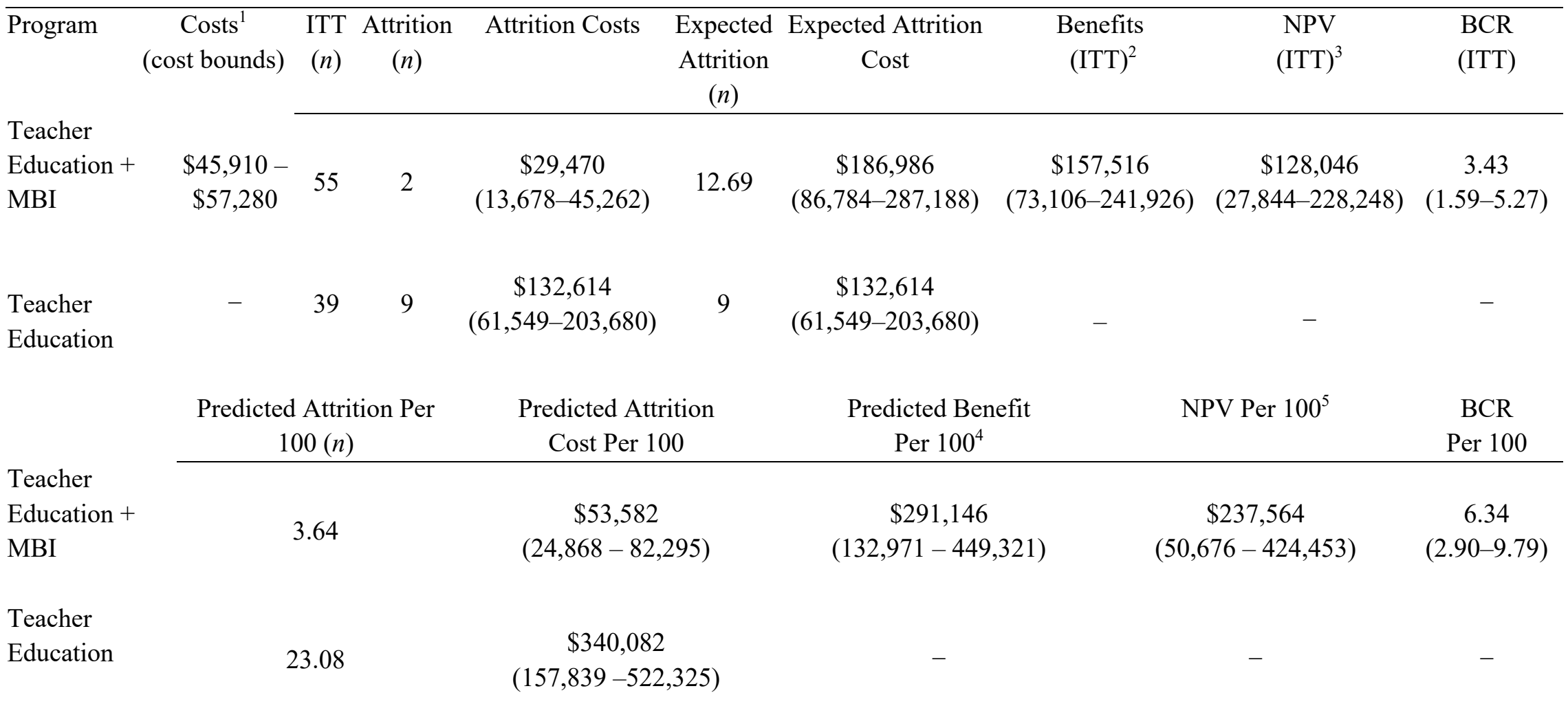

Note. ITT: Intention-to-treat sample. Attrition: Observed number of participants no longer teaching at year three. Expected attrition is based on the control group's observed attrition rate. Lower and upper attrition cost bounds are based inflation adjusted 2022 dollar costs of the low and high estimates of teacher replacement (Barnes et al., 2007; Shockley et al., 2006). MBI: the meditation-based intervention implemented in this study. NPV: Net Present Value or the benefits minus the actual costs. BCR: Benefit-cost ratio or the 
benefits divided by the costs.

1. MBI cost lower and upper bounds are the actual costs incurred and the costs incurred plus possible future costs, respectively.

2. ITT benefit is the expected attrition cost minus the observed attrition cost.

3. NPV is the ITT Benefits minus the actual cost.

4. Benefit Per 100 estimate is the difference between Teacher Education and Teacher Education + MBI Attrition costs Per 100 .

5. NPV Per 100 is the Benefit Per 100 minus the actual cost. 


\section{References}

Adnot, M., Dee, T., Katz, V., \& Wyckoff, J. (2017). Teacher turnover, teacher quality, and student achievement in DCPS. Educational Evaluation and Policy Analysis, 39(1), 54 76.

Baumert, J., \& Kunter, M. (2013). The COACTIV model of teachers' professional competence. In Cognitive activation in the mathematics classroom and professional competence of teachers (pp. 25-48). Springer.

Belfield, C., Bowden, A. B., \& Levin, H. M. (2018). Cost estimation in education: The ingredients method. In Teaching Benefit-Cost Analysis. Edward Elgar Publishing.

Billingsley, B., \& Bettini, E. (2019). Special Education Teacher Attrition and Retention: A Review of the Literature. Review of Educational Research, 89(5), 697-744. https://doi.org/10.3102/0034654319862495

Bind, M.-A. C., \& Rubin, D. B. (2020). When possible, report a Fisher-exact P value and display its underlying null randomization distribution. Proceedings of the National Academy of Sciences, 117(32), 19151-19158. https://doi.org/10.1073/pnas.1915454117

Borman, G. D., \& Dowling, N. M. (2008). Teacher Attrition and Retention: A Meta-Analytic and Narrative Review of the Research. Review of Educational Research, 78(3), 367-409. https://doi.org/10.3102/0034654308321455

Boyd, D., Grossman, P., Ing, M., Lankford, H., Loeb, S., \& Wyckoff, J. (2011). The influence of school administrators on teacher retention decisions. American Educational Research Journal, 48(2), 303-333.

Bush, G. W. (2001). No child left behind act of 2001. Retrieved April, 18, 2002. 
Crowley, D. M., Dodge, K. A., Barnett, W. S., Corso, P., Duffy, S., Graham, P., Greenberg, M., Haskins, R., Hill, L., Jones, D. E., Karoly, L. A., Kuklinski, M. R., \& Plotnick, R. (2018). Standards of Evidence for Conducting and Reporting Economic Evaluations in Prevention Science. Prevention Science, 19(3), 366-390. https://doi.org/10.1007/s11121017-0858-1

Dahl, C. J., Wilson-Mendenhall, C. D., \& Davidson, R. J. (2020). The plasticity of well-being: A training-based framework for the cultivation of human flourishing. Proceedings of the National Academy of Sciences. https://doi.org/10.1073/pnas.2014859117

DeAngelis, K. J., Wall, A. F., \& Che, J. (2013). The Impact of Preservice Preparation and Early Career Support on Novice Teachers' Career Intentions and Decisions. Journal of Teacher Education, 64(4), 338-355. Scopus. https://doi.org/10.1177/0022487113488945

Dee, T. S., \& Goldhaber, D. (2017). Understanding and addressing teacher shortages in the United States. The Hamilton Project, 5, 1-28.

Deen, M., \& de Rooij, M. (2020). ClusterBootstrap: An R package for the analysis of hierarchical data using generalized linear models with the cluster bootstrap. Behavior Research Methods, 52(2), 572-590. https://doi.org/10.3758/s13428-019-01252-y

DeMatthews, D. E., Knight, D. S., \& Shin, J. (2022). The Principal-Teacher Churn: Understanding the Relationship Between Leadership Turnover and Teacher Attrition. Educational Administration Quarterly, 58(1), 76-109. https://doi.org/10.1177/0013161X211051974

Digest of Education Statistics, 2019. (n.d.). National Center for Education Statistics. Retrieved April 30, 2021, from https://nces.ed.gov/programs/digest/d19/tables/dt19_303.60.asp 
Duckworth, A. L., Quinn, P. D., \& Seligman, M. E. (2009). Positive predictors of teacher effectiveness. The Journal of Positive Psychology, 4(6), 540-547.

Firth, D. (1993). Bias reduction of maximum likelihood estimates. Biometrika, 80(1), 27-38.

F.M. Hollands, Hanisch-Cerda, B., Levin, H. M., Belfield, C. R., Menon, A., Shand, R., Pan, Y., Bakir, I., \& Cheng, H. (2015). CostOut®.

Folkman, S., \& Lazarus, R. S. (1988). Coping as a mediator of emotion. Journal of Personality and Social Psychology, 54(3), 466.

García, E., \& Weiss, E. (2020). A policy agenda to address the teacher shortage in U.S. public schools. Economic Policy Institute, 55.

Goldberg, S. B., Riordan, K. M., Sun, S., \& Davidson, R. J. (2021). The Empirical Status of Mindfulness-Based Interventions: A Systematic Review of 44 Meta-Analyses of Randomized Controlled Trials. Perspectives on Psychological Science, 1745691620968771. https://doi.org/10.1177/1745691620968771

Goldhaber, D., Lavery, L., \& Theobald, R. (2015). Uneven Playing Field? Assessing the Teacher Quality Gap Between Advantaged and Disadvantaged Students. Educational Researcher, 44(5), 293-307. https://doi.org/10.3102/0013189X15592622

Goldhaber, D., \& Theobald, R. (2022). Teacher Attrition and Mobility in the Pandemic. Educational Evaluation and Policy Analysis, 01623737221139285. https://doi.org/10.3102/01623737221139285

Gray, L., \& Taie, S. (2015). Public School Teacher Attrition and Mobility in the First Five Years: Results from the First through Fifth Waves of the 2007-08 Beginning Teacher Longitudinal Study. First Look. NCES 2015-337. National Center for Education Statistics. https://eric.ed.gov/?id=ED556348 
Guin, K. (2004). Chronic teacher turnover in urban elementary schools. Education Policy Analysis Archives, 12, 42.

Guthery, S., \& Bailes, L. P. (2022). Patterns of Teacher Attrition by Preparation Pathway and Initial School Type. Educational Policy, 36(2), 223-246. https://doi.org/10.1177/0895904819874754

Henry, G. T., Bastian, K. C., \& Fortner, C. K. (2011). Stayers and Leavers: Early-Career Teacher Effectiveness and Attrition. Educational Researcher, 40(6), 271-280. JSTOR.

Hirshberg, M. J., Goldberg, S. B., Schaefer, S. M., Flook, L., Findley, D., \& Davidson, R. J. (2018). Divergent effects of brief contemplative practices in response to an acute stressor: A randomized controlled trial of brief breath awareness, loving-kindness, gratitude or an attention control practice. PloS One, 13(12), e0207765.

Hox, J. J., van de Schoot, R., \& Matthijsse, S. (2012). How few countries will do? Comparative survey analysis from a Bayesian perspective. Survey Research Methods, 6(2), 87-93.

Huang, F. L. (2018). Multilevel modeling myths. School Psychology Quarterly, 33(3), 492-499. https://doi.org/10.1037/spq0000272

Hue, M., \& Lau, N. (2015). Promoting well-being and preventing burnout in teacher education: A pilot study of a mindfulness-based programme for pre-service teachers in Hong Kong. Teacher Development, 19(3), 381-401. https://doi.org/10.1080/13664530.2015.1049748 Ingersoll, R. M., Merrill, E., Stuckey, D., \& Collins, G. (2018). Seven Trends: The Transformation of the Teaching Force - Updated October 2018. 28.

Jennings, P. A., Brown, J. L., Frank, J. L., Doyle, S., Oh, Y., Davis, R., Rasheed, D., DeWeese, A., DeMauro, A. A., Cham, H., \& Greenberg, M. T. (2017). Impacts of the CARE for Teachers Program on Teachers' Social and Emotional Competence and Classroom 
Interactions. Journal of Educational Psychology.

http://dx.doi.org.ezproxy.library.wisc.edu/10.1037/edu0000187

Jennings, P. A., \& Greenberg, M. T. (2009). The prosocial classroom: Teacher social and emotional competence in relation to student and classroom outcomes. Review of Educational Research, 79(1), 491-525.

Johnson, S. M. (2012). Having it both ways: Building the capacity of individual teachers and their schools. Harvard Educational Review, 82(1), 107-122. Scopus. https://doi.org/10.17763/haer.82.1.c8515831m501x825

Johnson, S. M., Kraft, M. A., \& Papay, J. P. (2012). How context matters in high-need schools: The effects of teachers' working conditions on their professional satisfaction and their students' achievement. Teachers College Record, 114(10). Scopus. https://www.scopus.com/inward/record.uri?eid=2-s2.084866930722\&partnerID $=40 \& m d 5=5 \mathrm{e} 7782655 \mathrm{c} 5 \mathrm{a} 3 \mathrm{~d} 5 \mathrm{ea} 7304 \mathrm{e} 018856341 \mathrm{~b}$

Kabat-Zinn, J. (1982). An outpatient program in behavioral medicine for chronic pain patients based on the practice of mindfulness meditation: Theoretical considerations and preliminary results. General Hospital Psychiatry, 4(1), 33-47.

Kabat-Zinn, J. (2013). Full catastrophe living, revised edition: How to cope with stress, pain and illness using mindfulness meditation. Hachette UK.

Kang, Y., Gray, J. R., \& Dovidio, J. F. (2014). The nondiscriminating heart: Lovingkindness meditation training decreases implicit intergroup bias. Journal of Experimental Psychology: General, 143(3), 1306.

Kemeny, M. E., Foltz, C., Cavanagh, J. F., Cullen, M., Giese-Davis, J., Jennings, P., Rosenberg, E. L., Gillath, O., Shaver, P. R., Wallace, B. A., \& Ekman, P. (2012). 
Contemplative/emotion training reduces negative emotional behavior and promotes prosocial responses. Emotion (Washington, D.C.), 12(2), 338-350.

https://doi.org/10.1037/a0026118

Kim, L. E., Jörg, V., \& Klassen, R. M. (2019). A Meta-Analysis of the Effects of Teacher Personality on Teacher Effectiveness and Burnout. Educational Psychology Review, 31(1), 163-195. Scopus. https://doi.org/10.1007/s10648-018-9458-2

Klusmann, U., Kunter, M., Trautwein, U., Lüdtke, O., \& Baumert, J. (2008). Teachers' occupational well-being and quality of instruction: The important role of self-regulatory patterns. Journal of Educational Psychology, 100(3), 702.

Kraft, M. A., Marinell, W. H., \& Shen-Wei Yee, D. (2016). School Organizational Contexts, Teacher Turnover, and Student Achievement: Evidence From Panel Data. American Educational Research Journal, 53(5), 1411-1449. Scopus. https://doi.org/10.3102/0002831216667478

Kruschke, J. (2014). Doing Bayesian data analysis: A tutorial with R, JAGS, and Stan. Kruschke, J. K. (2018). Rejecting or accepting parameter values in Bayesian estimation. Advances in Methods and Practices in Psychological Science, 1(2), 270-280.

Kush, J. M., Badillo-Goicoechea, E., Musci, R. J., \& Stuart, E. A. (2022). Teachers' mental health during the COVID-19 pandemic. Educational Researcher, 51(9), 593-597.

Lazarus, R. S., \& Folkman, S. (1984). Coping and adaptation. The Handbook of Behavioral Medicine, 282325.

Lindsay, E. K., \& Creswell, J. D. (2017). Mechanisms of mindfulness training: Monitor and Acceptance Theory (MAT). Clinical Psychology Review, 51(Supplement C), 48-59. https://doi.org/10.1016/j.cpr.2016.10.011 
MacKinnon, J. G., \& Webb, M. D. (2018). The wild bootstrap for few (treated) clusters. The Econometrics Journal, 21(2), 114-135. https://doi.org/10.1111/ectj.12107

McNeish, D., \& Stapleton, L. M. (2016). Modeling Clustered Data with Very Few Clusters. Multivariate Behavioral Research, 51(4), 495-518. https://doi.org/10.1080/00273171.2016.1167008

Mitchell, M. S., Greenbaum, R. L., Vogel, R. M., Mawritz, M. B., \& Keating, D. J. (2019). Can You Handle the Pressure? The Effect of Performance Pressure on Stress Appraisals, Selfregulation, and Behavior. Academy of Management Journal, 62(2), 531-552. https://doi.org/10.5465/amj.2016.0646

Nguyen, T. D., Pham, L. D., Crouch, M., \& Springer, M. G. (2020). The correlates of teacher turnover: An updated and expanded Meta-analysis of the literature. Educational Research Review, 31, 100355. https://doi.org/10.1016/j.edurev.2020.100355

Papay, J. P., \& Kraft, M. A. (2015). Productivity returns to experience in the teacher labor market: Methodological challenges and new evidence on long-term career improvement. Journal of Public Economics, 130, 105-119.

Peyton, D. J., Acosta, K., Harvey, A., Pua, D. J., Sindelar, P. T., Mason-Williams, L., Dewey, J., Fisher, T. L., \& Crews, E. (2021). Special education teacher shortage: Differences between high and low shortage states. Teacher Education and Special Education, 44(1), 5-23.

Rockoff, J. E. (2004). The impact of individual teachers on student achievement: Evidence from panel data. The American Economic Review, 94(2), 247-252.

Roeser, R. W., Schonert-Reichl, K. A., Jha, A., Cullen, M., Wallace, L., Wilensky, R., Oberle, E., Thomson, K., Taylor, C., \& Harrison, J. (2013). Mindfulness training and reductions 
in teacher stress and burnout: Results from two randomized, waitlist-control field trials. Journal of Educational Psychology, 105(3), 787-804. https://doi.org/10.1037/a0032093

Roeser, R. W., Skinner, E., Beers, J., \& Jennings, P. A. (2012). Mindfulness training and teachers' professional development: An emerging area of research and practice. Child Development Perspectives, 6(2), 167-173.

Ronfeldt, M. (2021). Links Among Teacher Preparation, Retention, and Teaching Effectiveness. Evaluating and Improving Teacher Preparation Programs. Evaluating and Improving Teacher Preparation Programs. https://doi.org/10.31094/2021/3/1

Ronfeldt, M., Bardelli, E., Truwit, M., Mullman, H., Schaaf, K., \& Baker, J. C. (2020). Improving Preservice Teachers' Feelings of Preparedness to Teach Through Recruitment of Instructionally Effective and Experienced Cooperating Teachers: A Randomized Experiment. Educational Evaluation and Policy Analysis, 42(4), 551-575. https://doi.org/10.3102/0162373720954183

Ronfeldt, M., Loeb, S., \& Wyckoff, J. (2013). How Teacher Turnover Harms Student Achievement. American Educational Research Journal, 50(1), 4-36. https://doi.org/10.3102/0002831212463813

Ryan, S. V., von der Embse, N. P., Pendergast, L. L., Saeki, E., Segool, N., \& Schwing, S. (2017). Leaving the teaching profession: The role of teacher stress and educational accountability policies on turnover intent. Teaching and Teacher Education, 66, 1-11. https://doi.org/10.1016/j.tate.2017.03.016

Shockley, R., Guglielmino, P., \& Watlington, E. (2006). A National Crisis in Teacher Education: What Are the Costs? 6. 
Simon, N. S., \& Johnson, S. M. (2015). Teacher turnover in high-poverty schools: What we know and can do. Teachers College Record, 117(3). Scopus. https://www.scopus.com/inward/record.uri?eid=2-s2.085068427828\&partnerID=40\&md5=306f6b53b9fc0228db2f8a11643acd8c

Sorensen, L. C., \& Ladd, H. F. (2020). The Hidden Costs of Teacher Turnover. AERA Open, 6(1), 2332858420905812. https://doi.org/10.1177/2332858420905812

US Department of Education. (2019, April 11). Awards-Teacher Incentive Fund [Abstracts; Notifications of Award; Persons]. US Department of Education (ED). https:/www2.ed.gov/programs/teacherincentive/awards.html

US Department of Education. (2021). Digest of Education Statistics, 2020. National Center for Education Statistics. https://nces.ed.gov/programs/digest/d20/tables/dt20_208.20.asp

Vagi, R., Pivovarova, M., \& Miedel Barnard, W. (2019). Keeping Our Best? A Survival Analysis Examining a Measure of Preservice Teacher Quality and Teacher Attrition. Journal of Teacher Education, 70(2), 115-127. https://doi.org/10.1177/0022487117725025

Wiggan, G., Smith, D., \& Watson-Vandiver, M. J. (2021). The national teacher shortage, urban education and the cognitive sociology of labor. The Urban Review, 53(1), 43-75.

Wynn, S. R., Carboni, L. W., \& Patall, E. A. (2007). Beginning Teachers' Perceptions of Mentoring, Climate, and Leadership: Promoting Retention through a Learning Communities Perspective. Leadership and Policy in Schools, 6(3), 209-229. https://doi.org/10.1080/15700760701263790

Walker, T. (2022, February 1). Survey: Alarming Number of Educators May Soon Leave the Profession. National Education Association. https://www.nea.org/advocating-for- 
change/new-from-nea/survey-alarming-number-educators-may-soon-leave-

profession?utm_source $=$ neatoday\&utm medium $=$ email\&utm campaign $=20220209$ neato day\&utm_content $=$ survey $\&$ ms $=20220209$ NEAToday 


\section{Supplemental Materials}

Table S1.

Balance Between Intervention and Control Groups

\begin{tabular}{|c|c|c|c|c|c|}
\hline \multirow[t]{2}{*}{ Variable } & \multicolumn{2}{|c|}{ Control } & \multicolumn{2}{|c|}{ Intervention } & \multirow[b]{2}{*}{$p$-Value } \\
\hline & Mean / n (\%) & SD & Mean / n (\%) & $\mathrm{SD}$ & \\
\hline Age & 21.90 & $(0.59)$ & 22.84 & $(5.11)$ & .674 \\
\hline \multicolumn{6}{|l|}{ Gender } \\
\hline Female & $41(100)$ & & $54(94.74)$ & & .722 \\
\hline Male & $0(0)$ & & $3(5.26)$ & & \\
\hline \multicolumn{6}{|l|}{ Race } \\
\hline Black / African American & $2(4.88)$ & & $1(1.75)$ & & .905 \\
\hline Asian / Pacific Islander & $2(4.88)$ & & $2(3.51)$ & & \\
\hline Hispanic & $3(7.32)$ & & $2(3.51)$ & & \\
\hline White / Caucasian & $33(80.49)$ & & $51(89.47)$ & & \\
\hline Mixed Race & $1(2.44)$ & & $1(1.75)$ & & \\
\hline Teaching right career & 4.29 & $(0.81)$ & 4.29 & $(0.63)$ & .667 \\
\hline Happy teaching & 8.80 & $(1.10)$ & 8.88 & $(1.56)$ & .905 \\
\hline Want mindfulness & 8.88 & $(1.77)$ & 9.46 & $(1.21)$ & .062 \\
\hline Positive affect & 33.24 & $(6.50)$ & 35.63 & $(5.43)$ & .667 \\
\hline Negative affect & 21.49 & $(4.92)$ & 21.09 & $(6.12)$ & .905 \\
\hline Implicit positive affect & 2.06 & $(0.48)$ & 2.14 & $(0.47)$ & .835 \\
\hline Implicit negative affect & 1.77 & $(0.34)$ & 1.84 & $(0.32)$ & .722 \\
\hline Mindfulness & 122.63 & $(15.00)$ & 124.04 & $(15.99)$ & .905 \\
\hline Depression & 0.94 & $(0.66)$ & 0.94 & $(0.47)$ & .667 \\
\hline Anxiety & 0.53 & $(0.43)$ & 0.57 & $(0.54)$ & .905 \\
\hline Emotional Exhaustion & 18.6 & $(9.19)$ & 18.97 & $(10.06)$ & .917 \\
\hline Personal Accomplishment & 38.24 & $(6.36)$ & 38.24 & $(5.62)$ & .917 \\
\hline Depersonalization & 4.20 & $(3.47)$ & 4.20 & $(4.05)$ & .835 \\
\hline Perceived stress & 21.22 & $(5.63)$ & 21.47 & $(5.77)$ & .917 \\
\hline Self-efficacy & 30.32 & $(3.41)$ & 30.53 & $(3.67)$ & .905 \\
\hline Extraversion & 8.17 & $(3.30)$ & 8.88 & $(2.79)$ & .722 \\
\hline Agreeableness & 10.59 & $(2.14)$ & 10.79 & $(2.17)$ & .905 \\
\hline Conscientiousness & 11.59 & $(2.33)$ & 11.96 & $(2.16)$ & .835 \\
\hline Emotional stability & 8.56 & $(2.61)$ & 8.54 & $(2.94)$ & .976 \\
\hline Openness to experience & 10.22 & $(2.08)$ & 11.02 & $(2.13)$ & .667 \\
\hline Psychological well-being & 188.15 & $(22.07)$ & 194.96 & $(19.96)$ & .667 \\
\hline Emotional style & 88.44 & $(10.02)$ & 88.44 & $(10.75)$ & .723 \\
\hline Instructional supports & 2.88 & $(1.03)$ & 2.62 & $(0.97)$ & .723 \\
\hline Emotional supports & 4.77 & $(0.98)$ & 4.65 & $(1.11)$ & .905 \\
\hline Classroom organization & 5.11 & $(1.43)$ & 4.91 & $(1.24)$ & .835 \\
\hline Race bias (adult faces) & 0.31 & $(0.37)$ & 0.36 & $(0.37)$ & .835 \\
\hline Race bias (child faces) & 0.23 & $(0.31)$ & 0.32 & $(0.29)$ & .674 \\
\hline Emotion regulation & 3.99 & $(0.99)$ & 4.12 & $(0.91)$ & .835 \\
\hline
\end{tabular}

Note. $P$-values are false discovery rate corrected. "Teaching right career," "happy teaching," and

"want mindfulness" were single items rated on 1 (strongly disagree) to 5 (strongly agree), 1 (very 
unhappy) to 10 (very happy), and 1 (not at all interested) to 10 (extremely interested) scales, respectively. General and implicit positive and negative affect were assessed with Positive and Negative Affect Schedule (Watson et al., 1988) and the Implicit Positive and Negative Affect Test, respectively (Quirin et al., 2009). Mindfulness was assessed with the Five Facet Mindfulness Questionnaire (Baer et al., 2008). Depression and anxiety were assessed with the Symptoms Checklist 90-R (Derogatis, 1992). Burnout (emotional exhaustion through depersonalization) was assessed with the Maslach Burnout Inventory - Educator Survey (Maslach et al., 1996). Personality facets (extraversion through openness to experience) were assessed with the 10-item Big Five Inventory (Rammstedt \& John, 2007). Healthy emotionality was assessed with the Emotional Styles Questionnaire (Kesebir et al., 2019). Classroom behaviors (Instructional supports through classroom organization) were rated by certified Classroom Assessment Scoring System observers (La Paro et al., 2004). Automatic race bias was assessed with the adult and child versions of the Black/White implicit association test, respectively (Greenwald et al., 2003). Emotion regulation was assessed with Emotional Go/No go task (Hare et al., 2008). Dprime is an index of task accuracy after accounting for response bias. 


\section{Table S2.}

\section{Statistical Software and Packages}

\begin{tabular}{|c|c|}
\hline Software / Package & Reference \\
\hline $\mathrm{R}$ & $\begin{array}{l}\text { R Core Team. (2021). R: A language and environment for statistical computing. } R \\
\text { Foundation for Statistical Computing, Vienna, Austria. ISBN 3-900051-07-0. }\end{array}$ \\
\hline G*Power3.1 & $\begin{array}{l}\text { Faul, F., Erdfelder, E., Buchner, A., \& Lang, A.-G. (2009). Statistical power analyses } \\
\text { using G* Power 3.1: Tests for correlation and regression analyses. Behavior } \\
\text { Research Methods, 41(4), 1149-1160. }\end{array}$ \\
\hline $\operatorname{lme} 4$ & $\begin{array}{l}\text { Bates, D., Mächler, M., Bolker, B., \& Walker, S. (2015). Fitting Linear Mixed-Effects } \\
\text { Models Using lme4. Journal of Statistical Software, 67(1). } \\
\text { https://doi.org/10.18637/jss.v067.i01 }\end{array}$ \\
\hline \multirow[t]{3}{*}{ sandwich } & 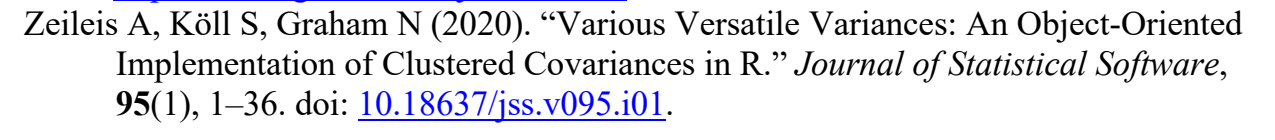 \\
\hline & $\begin{array}{l}\text { Zeileis A (2004). "Econometric Computing with HC and HAC Covariance Matrix } \\
\text { Estimators." Journal of Statistical Software, 11(10), 1-17. doi: } \\
\text { 10.18637/jss.v011.i10. }\end{array}$ \\
\hline & $\begin{array}{l}\text { Zeileis A (2006). "Object-Oriented Computation of Sandwich Estimators." Journal of } \\
\text { Statistical Software, 16(9), 1-16. doi: } 10.18637 / \text { jss.v016.i09. }\end{array}$ \\
\hline logistsf & $\begin{array}{l}\text { Heinze, G., Ploner, M., Dunkler, D., \& Southworth, H. (2013). Firth's bias reduced } \\
\text { logistic regression. R package version, } 1,33 \text {. }\end{array}$ \\
\hline brms & $\begin{array}{l}\text { Bürkner, P. C. (2017). brms: An R package for Bayesian multilevel models using Stan. } \\
\text { Journal of statistical software, } 80,1-28 \text {. }\end{array}$ \\
\hline bayestestR & $\begin{array}{l}\text { Makowski, D., Lüdecke, D., Ben-Shachar, M. S., Wilson, M. D., Bürkner, P. C., \& Mahr, } \\
\text { T. (2020). Package 'bayestestR'. last viewed August, 20, } 2020 .\end{array}$ \\
\hline Tidyverse & $\begin{array}{l}\text { Wickham, H., Averick, M., Bryan, J., Chang, W., McGowan, L. D. A., François, R., ... \& } \\
\text { Yutani, H. (2019). Welcome to the Tidyverse. Journal of open source software, } \\
\text { 4(43), } 1686 .\end{array}$ \\
\hline ClusterBoostrap & $\begin{array}{l}\text { Deen M, de Rooij M (2020). "ClusterBootstrap: An R package for the analysis of } \\
\text { hierarchical data using generalized linear models with the cluster bootstrap." } \\
\text { Behavior Research Methods, 52(2), 572-590. https://doi.org/10.3758/s13428-019- } \\
\text { 01252-y. }\end{array}$ \\
\hline
\end{tabular}




\section{Intervention}

The intervention was partially integrated into the teacher education program. Thirty minutes of the mandatory weekly cohort seminar time was dedicated to the intervention for cohorts assigned to treatment. All cohort students received this 30-minutes of the intervention regardless of their status as research study participants. Research participants also engaged in 60minutes of additional intervention before or after cohort seminar, depending on cohort schedule availability, for a total of 90-minutes per week of intervention. In addition, two 4-hour intensive "retreat" days that involved little didactic instruction focusing almost entirely on formal mindfulness and connection practices were also part of the intervention (21.5 hours total). During the following semester (i.e., the final of the teacher education program), 15-minute weekly booster practices were done during each cohort seminar. Once per month intervention instructors were present in person to answer practice-related questions. The other booster sessions followed a pre-established sequence of recorded mindfulness and connection practices.

The following description of the intervention is adapted from Blinded authors (under review), in which the authors present pre-, post-, and 6-month follow-up effects (i.e., not longterm follow-up) on an outcome unrelated to the current results and not assessed during the longterm follow-ups.

The intervention has roots in Mindfulness-Based Stress Reduction (Kabat-Zinn, 2013) and Tibetan Buddhist approaches to mind-training. A novel secularized theory of change derived from Buddhist philosophy (Thrangu \& Thrangu, 2004) was added to common presentations of mindfulness training. Based on the notion in Buddhist traditions that a conceptual understanding of the process of training the mind (i.e., the view) is an important element in learning mediation (Rinpoche, 1993), the view in this training was intended to provide appropriate mindsets for approaching mindfulness, loving-kindness, and intention/motivation practices in the context of 
learning to teach. For example, the view component of the third class was that desired qualities of mind like calmness and equanimity are already present but habitual approaches to experience (e.g., aversion to unwanted experiences) prevent qualities such as contentment from being noticed. The intent of this view is to shift purpose away from changing experience toward an openness to experiencing whatever is arising.

Mindfulness instruction emphasized: a) building clear awareness of the contents of the present moment (i.e., thoughts, sensations, emotions) and an attitude of calmly resting with whatever contents arise, even if they are unpleasant; b) strengthening the capacity to maintain an on-going, background monitoring of experience (i.e., meta-awareness) so that if the mind becomes distracted, agitated or reactive, awareness of these processes quickly arises and c) using increased awareness and meta-awareness as a workspace in which response rather than habit or reaction drive behavior.

Connection practices included loving-kindness practices and compassion practices that seek to extend kindness and a desire to help relieve the difficulties of an ever-larger sphere of people. For example, the Just like me practice leads participants through a reflection on how everyone is just like me in sharing the basic desire to be happy and to avoid difficulty. This practice can be focused on those we feel close to or those we struggle with. Intention practices were intended to help participants clarify the intention and purpose that led them to enter the teacher education program and strengthen the prosocial elements of that intention (Authors, 2020). 
Below are the overarching tenets behind the construction of the intervention and example lesson.

For intervention content, please cite: Hirshberg, M.J., Hase, D., Gustofason, L. \& Thomas-

Prince, L. (2015). Well-Being Training for Preservice Teachers: A 9-Week Mindfulness and

Connection-Based Intervention.

\section{Purpose}

- To develop competencies that support well-being, effective classroom management, and persistence in teaching.

\section{Key skills:}

\section{- Self-awareness}

- Awareness of bodily sensations

- Awareness of emotions

- Awareness of thoughts

\section{- Self-regulation}

- Learning to respond rather than react

- Attention

\section{- Acceptance}

- Stability

- Flexibility

- Able to rest into experience as it is in this moment

- Equanimity

O Not needing to change experience in any way, at least for a moment. Able to maintain a sense of ease and calmness as experience rises and falls.

- Mindfulness

○ Generally

- To remember; to maintain a knowing awareness.

- During practice

- Remembering to bring the mind back to object of the practice.

\section{- Kindness}

- Getting in touch with and developing our basic sense of goodwill toward others (and our own condition)

\section{Key points of the view of practice}

1. Curiosity - be willing to look without knowing what you will find.

2. The qualities of happiness and well-being reflect the basic nature of the mind, so by looking and seeing with equanimity, we are slowly allowing these qualities to come out.

3. We can find ease and well-being even in the midst of turmoil.

4. To find ease and well-being, we must experience that we experience thoughts, emotions, sensations etc., but we more than these.

5. The suffering of suffering. 
6. The power of intention is mindfulness.

7. Awareness has room for everything.

8. All experience is impermanent.

9. Attachment and aversion.

10. Interconnectedness

Week one (introduction, Coming into the body)

\section{Example lesson}

Theme: Introduce mindfulness and how it is related to health and well-being. Participants will practice mindfulness-based skills using the body as an anchor.

Attitude- Curiosity

10 min: 6-point body scan

- Emphasize in instructions just letting be into whatever sensations are arising, and gently inviting the mind back when it has wandered. Whatever you experience is fine just as it is.

\section{0 min: Overview of course and view of practice part I:}

- Welcome.

- Introduce mindfulness as a way of being - stepping out of autopilot. Mindfulness is paying attention in the present moment on purpose w/o judgment (or w/ awareness of judgment). It's a practice, something we will try out on a regular basis.

- Mindfulness is also translated as "to remember." As we learn this practice, we will over and over again be remembering to keep attention on the object of the practice. In life, we can remember in every moment to bring attention to whatever it is we are doing - reading, listening, speaking, etc.

- Note that each class will introduce and reinforce a key practice, and a key attitude. Attitudes are approaches to practice and life that can help us to remember, to be mindful.

- Today's attitude is Curiosity. Curiosity is the willingness to look. In all of the practices we learn, curiosity is always the first step. Just be curious and willing to try the practices, and to look at what arises in experiences. Curiosity also has the quality of not knowing. That is, when we are curious we are looking to see what is there, not looking to confirm what we think we already know to be. This quality of not-knowing, of simply looking and seeing what arises is what we will bring to practice today.

- Brief instructor introductions.

- How and why you came to practice and what it has done for you. Emphasize role in teaching. 


\section{0 min. Meet participants:}

- Expectations? Hopes? What do you know about mindfulness? Hesitations or fears?

5 min. Share Ojai council rules - agreements in how to be together during this time.

- Speak from own experience. Listen deeply (no side conversations, cell phone use etc.). Confidentiality, emphasize that this class is for them...just experience it.

\section{5 min. Holding breath in belly (Vase) breathing \& Body scan}

- Emphasize the "coming into the body and out of the head" aspect of vase breathing. Note that should not be forced or strained. Hold at own pace.

- Body scan - emphasize curiosity of physical sensations. Normalcy of distracted mind. Mindfulness as the moment of recognizing the mind has wandered and inviting it back (remembering).

\section{0 min. Check-in}

\section{5 min. Introduce pause practice}

5 min. Group share on pause, practicing pause before speaking.

- Notice whether communicating in this way is different

$10 \mathrm{~min}$. Overview of practice and the practice during the week.

- Difference between formal and informal.

- Filling out practice logs.

- How to access practice tracks etc.

Practice this week:

- Vase breath and formal body scan everyday ( $20 \mathrm{~min}$ )

- At least one 6-point, informal body scan each day ( 2 min)

- Pause at least once a day 


\section{References}

Baer, R. A., Smith, G. T., Lykins, E., Button, D., Krietemeyer, J., Sauer, S., Walsh, E., Duggan, D., \& Williams, J. M. G. (2008). Construct Validity of the Five Facet Mindfulness Questionnaire in Meditating and Nonmeditating Samples. Assessment, 15(3), 329-342. https://doi.org/10.1177/1073191107313003

Dahl, C. J., Wilson-Mendenhall, C. D., \& Davidson, R. J. (2020). The plasticity of well-being: A training-based framework for the cultivation of human flourishing. Proceedings of the National Academy of Sciences. https://doi.org/10.1073/pnas.2014859117

Derogatis, L. R. (1992). SCL-90-R: Administration, scoring and procedures manual for the $R$ (evised) version and other instruments of the psychopathology rating scale series. Clinical Psychometric Research.

Greenwald, A. G., Nosek, B. A., \& Banaji, M. R. (2003). Understanding and using the implicit association test: I. An improved scoring algorithm. Journal of Personality and Social Psychology, 85(2), 197.

Hare, T. A., Tottenham, N., Galvan, A., Voss, H. U., Glover, G. H., \& Casey, B. J. (2008). Biological Substrates of Emotional Reactivity and Regulation in Adolescence During an Emotional Go-Nogo Task. Biological Psychiatry, 63(10), 927-934. https://doi.org/10.1016/j.biopsych.2008.03.015

Hoffman MD, Gelman A (2014). ŞThe No-U-Turn Sampler: Adaptively Setting Path Lengths in Hamiltonian Monte Carlo. ̌̌ The Journal of Machine Learning Research, 15(1), 1593 Ü

1623.Kabat-Zinn, J. (2013). Full catastrophe living, revised edition: How to cope with stress, pain and illness using mindfulness meditation. Hachette UK. 
Kesebir, P., Gasiorowska, A., Goldman, R., Hirshberg, M. J., \& Davidson, R. J. (2019). Emotional Style Questionnaire: A multidimensional measure of healthy emotionality. Psychological Assessment, 31(10), 1234-1246. https://doi.org/10.1037/pas0000745

Kruschke, J. (2014). Doing bayesian data analysis: A tutorial with r, JAGS, and stan. Academic Press.

La Paro, K. M., Pianta, R. C., \& Stuhlman, M. (2004). The Classroom Assessment Scoring System: Findings from the Prekindergarten Year. The Elementary School Journal, 104(5), 409-426. https://doi.org/10.1086/499760

Maslach, C., Jackson, S. E., \& Leiter, M. P. (1996). Maslach burnout inventory manual . Mountain View, CA: CPP. Inc., and Davies-Black.

Quirin, M., Kazén, M., \& Kuhl, J. (2009). When nonsense sounds happy or helpless: The implicit positive and negative affect test (IPANAT). Journal of Personality and Social Psychology, 97(3), 500.

Rammstedt, B., \& John, O. P. (2007). Measuring personality in one minute or less: A 10-item short version of the Big Five Inventory in English and German. Journal of Research in Personality, 41(1), 203-212. https://doi.org/10.1016/j.jrp.2006.02.001

Rinpoche, P. (1993). The Heart Treasure of the Enlightened Ones: The Practice of View, Meditation, and Action. Shambhala Publications.

Thrangu, K., \& Thrangu, R. (2004). An Ocean of the Ultimate Meaning: Teachings on Mahamudra: a Commentary on Wangchuk Dorje's Ngedön Gyamtso. Shambhala Publications.

Watson, D., Clark, L. A., \& Tellegen, A. (1988). Development and validation of brief measures of positive and negative affect: The PANAS scales. Journal of Personality and Social 
Psychology, 54(6), 1063. 